\title{
Hybrid evolutionary oligopolies and the dynamics of corporate social responsibility
}

\author{
Tomáš Tichý $^{1} \cdot$ Davide Radi $^{1,2} \cdot$ Fabio Lamantia ${ }^{1,3}$ (D)
}

Received: 14 May 2020 / Accepted: 25 September 2020 / Published online: 13 October 2020

(C) The Author(s) 2020

\begin{abstract}
The diffusion of corporate social responsibility is investigated by employing a hybrid evolutionary game where a firm chooses between being either socially responsible, which implies devoting a fraction of its profit to social projects, or non-socially responsible. Consumers prize socially responsible companies by paying a higher reservation price for their products. The hybrid evolutionary framework is characterized by a quantity dynamics that describes the oligopolistic competition given firms' belief about the composition of the industry. At regular intervals of time, this belief is endogenously updated by a retrospective comparison on the profits obtained and on the basis of an evolutionary mechanism. Assuming that firms are Nash players, that is at each instant of time they produce the Nash equilibrium-in-belief quantity, the investigation of the model reveals that an industry homogeneously populated by socially responsible firms is a stable equilibrium when the fraction of profits earmarked for socially responsible activities is sufficiently limited. However, the extra marginal profits of a socially responsible firm are reduced when the number of competitors increases, impeding the diffusion of socially responsible companies. In particular, the trade-off between a higher net margin on sales obtained by socially responsible firms and a lower level of production that reduces the profit gap between a socially responsible firm and the rest of the market shows that an increased size of the industry favors mixed oligopolies. Moreover, imposing the hypothesis of neutrality of CSR activities, the model reveals that being socially responsible is an evolutionarily stable strategy for firms and is convenient for customers. Relaxing the hypothesis of Nash players by introducing boundedly rational firms that decide their level of production according to a partial adjustment toward the best reply, the robustness of these results is confirmed.
\end{abstract}

Keywords Corporate social responsibility $\cdot$ Cournot market $\cdot$ Hybrid evolutionary games. 


\section{Introduction}

The inclusion of social strategies in the main corporate objectives is a widely debated issue among academics and leading experts. The more traditional vision, authoritatively defended by M. Friedman [see "The social responsibility of business is to increase its profits" in Friedman (1970)], regards the maximization of profits as the only objective for all shareholders and considers other activities only as losses both in the value and in the focus of a company. On the other hand, the pursuit of social strategies in addition to those purely related to profits has been associated with the creation of important corporate values and pursues higher objectives that society as a whole expects from its economic protagonists, as more recently remarked in Porter and Kramer (2002).

An example of social strategy is that of corporate philanthropy and, more generally, of corporate social responsibility (CSR, hereafter) which, as clarified in Seitanidi and Crane (2009), allows "the alignment of strategic business interests with societal expectations.” The paradigm of including CSR activities into firms' actions is nowadays considered more appropriate for correct business management. In practice, many companies carry out CSR actions at various levels and with varying intensity. It is now common practice, in fact, to issue a social report with international standards for CSR activities; see UNI ISO 26000:2010 on Social Responsibility, ${ }^{1}$ although activities of this kind are not a legal requirement for firms but only encouraged by, for example, the European-Union law, see directive 2014/95/EU, through a comply-or-explain principle. Corporate philanthropy and CSR can be also interpreted as strategic devices, linking these activities with the potential advantages that they bring to firms in terms of staff motivation, increase in reputation, and decrease in $R \& D$ costs; see on this point Smith (1994) and Hillman and Keim (2001).

Abstracting from motivational or reputational aspects, the current work questions the endogenous adoption of CSR-like strategies in an oligopoly market, which is populated by profit-oriented firms and is represented by a dynamic model. An element of peculiarity of the model is the assumption that firms form beliefs about the composition of the oligopoly market, and they estimate the probability that a competitor is a socially responsible company according to an evolutionary scheme and trust this belief for a given window of time. On the contrary, the decision about the output to produce is revised continuously on the basis of the expected level of production of the competitors.

The asynchronous decision process of the firms is represented by a hybrid evolutionary oligopoly model. A hybrid evolutionary model is an evolutionary model in which the purely evolutionary aspect of the system evolves with a different time scale than that of other system states. See, e.g., Bischi et al. (2013a,b) and Lamantia and Radi (2015), for applications of hybrid evolutionary models to describe the diffusion of environmentally friendly technologies, or practices, in the fishery industry. This modeling framework generalizes, therefore, the classical evolutionary games used for modeling players' updating process of the strategy to adopt or the behavioral rule to follow. See Droste et al. (2002), Bischi et al. (2015) and Hommes et al. (2018) for

\footnotetext{
$\overline{1 \text { https://www.iso.org/iso-26000-social-responsibility.html. }}$
} 
examples of evolutionary oligopoly games, of non-hybrid type, where firms select the behavioral rules to determine a response plan to the strategies of the opponents.

In the scientific debate on the economic sustainability of socially responsible behaviors or practices, evolutionary models have been employed for studying "mixed" markets, where firms can maximize objective functions that include non-profit components. In particular, the best relative performances are not always obtained by profit-maximizing firms and mixed market configurations may endogenously arise, see, among others, Heifetz et al. (2007), Koçkesen et al. (2000) and Bendle and Vandenbosch (2014). Relatedly, Königstein and Müller (2001) show that under evolutionary pressure the inclusion of a share of consumer surplus in the firm's objective function may provide strategic advantages to the firm.

A specific application of evolutionary games in an oligopoly model with CSR activities is studied in Kopel et al. (2014), which is the contribution most closely related to this work. In Kopel et al. (2014), the choices related to CSR activities lead to a variation of the firm's objective function, in which CSR activities translate to the maximization of profits plus a share of the consumer surplus, extending Kopel and Brand (2012) to an evolutionary setup. All in all, Kopel et al. (2014) shows that in some cases the social strategy can be beneficial for shareholders in order to gain a competitive advantage over opponents. Kopel and Lamantia (2018) deals with the model of Kopel et al. (2014) and explores the effect of increasing competition pressure on CSR activities. In that paper, it is shown that in some cases an inverse U-shaped relationship arises between the long-term survival of social strategy and the intensity of competition.

Compared to Kopel et al. (2014) and Kopel and Lamantia (2018), the current model introduces an interpretation of CSR more focused on charity actions ("corporate philanthropy") or socially responsible projects (such as investments devoted to reducing the carbon footprint) and therefore proposes a different objective function for CSR firms with respect to the mentioned contributions. Specifically, we propose a simple "mixed" oligopolistic model with competition between traditional firms, which maximize their profits in each period, and firms oriented towards CSR behavior, which allocate part of their profit to charities or for projects aimed to reduce environmental, social and corporate government risks, instead of maximizing their profits plus a share of the consumer surplus as in Kopel et al. (2014) and Kopel and Lamantia (2018). The "target-less approach" adopted is consistent with the recent legislation which, on the basis of the explain-or-comply principle, requires to generate a non-financial document that contains information about how much funds are devoted to certain CSR activities. ${ }^{2}$ Based on the information on the CSR reports, a company undertakes actions of CSR disclosure. Although the final product provided by firms satisfies the

\footnotetext{
2 An example is the CSR report (also known as sustainability report) by Danfoss (a Danish multinational company that manufactures products and provides services used in: cooling food, air conditioning, heating buildings, variable-frequency drivers, gas compressors, powering mobile machinery), which indicates company's energy and climate strategies based on investing in energy-savings and renewable energy to manage potential environmental risks. This report indicates, for example, that the company is committed to change its company car fleet to become all electric latest by 2030. Obviously, the firm does not indicate the fraction of profits devoted to CSR activities (to change the car fleet), however, the mentioned strategies are costly and imply to invest part of the profits. In the stylized representation of the reality offered by the current model, the CSR actions of company's are proxied by the fraction of profits devoted to CSR activity.
} 
same needs of consumers, thanks to the mentioned actions of CSR disclosure the CSR activity of a company increases the consumers' willingness to pay for the purchase of its products, see Manasakis et al. (2014). In this way, the final consumer faces a dichotomous choice when buying the good: she/he can pay a lower price knowing that the company from which she/he buys will not carry out any "socially responsible" behavior or she/he can decide to pay a surcharge and see part of his expenses go to charitable activities. As in Kopel et al. (2014), the solidarity aspect introduces, therefore, an effect that is in some way analogous to vertical product differentiation, despite products are "physically" homogeneous. The product of the socially responsible firms, therefore, can satisfy a need of the consumer who can be willing to spend more to contribute to good initiatives. This choice by the consumer is free as long as s/he can also buy cheaper goods manufactured by pure profit-maximizing firms. The existence of socially responsible firms and profit-maximizing firms depends on strategic aspects. In fact, a firm is corporate socially responsible or pure-profit maximizer according to which strategy proves to be successful, i.e., it is able to win the competition of the best relative performance.

The employed objective function for socially responsible firm, which is different from the one in Kopel et al. (2014) and Kopel and Lamantia (2018), is already an addition to the current literature. In fact, the concept of CSR is broader than that considered here, or in Kopel et al. (2014) and Kopel and Lamantia (2018), and adds to the profits those considerations related to society and the environment in the so-called triple bottom line, see Elkington (1994). In the proposed model, on the other hand, the CSR action is configured as devolution of profit in these activities so that in the model we abstract on the effective use of resources set aside for social activity. Compared to Kopel et al. (2014) and Kopel and Lamantia (2018), a further modeling innovative choice is the process of updating beliefs which is asynchronous with respect to the output decision process and the frequency of updating beliefs is parametrized. To complete the modeling framework, a possible cost for charity is considered, with the marginal costs of the socially responsible firms that may be larger to account for such a cost.

Modeling firms as Nash players, that is, they produce the Bayesian-Cournot Nash equilibrium quantities as in Kopel et al. (2014), the stability of the Bayesian-Cournot Nash equilibria is investigated as a function of the fraction of profits donated for charity or invested in socially responsible projects by CSR firms. ${ }^{3}$ In particular, the higher propensity of consumers to pay for products realized by socially responsible firms is considered fixed and the amount of profits devoted to charity is left to vary. Therefore, the investigation regards a situation in which consumers are willing to pay more because a firm is socially responsible and devote a certain fraction of its own profits to charity or to finance social projects but independently of how much charity activity and

\footnotetext{
3 For any company, it is more and more popular to donate part of profits/revenues to promote social activities, such as sport, environment. An example is represented by the agenda Tech4Good in the USA, with companies that invest part of their profits in corporate volunteering and in non-profit activities aimed at improving people's lives. Microsoft, for example, is the champion of the so-called corporate philanthropy. At the same time, more and more important are the investments and actions devoted to mitigate the environmental, social and governance (ESG) risks coming from a company's activity; see the ESG regulation and branding.
} 
socially responsible activity are effectively conducted. Parameterizing the willingness to pay and the fraction of profit devoted to CSR activity offers modeling flexibility that captures the heterogeneity of targets and interests that CSR activities aim to reach and which are difficult to represent with a single objective function. The analysis of the dynamics of the model reveals that an industry homogeneously populated by socially responsible companies is a stable equilibrium when the fraction of profits earmarked for socially responsible activities is sufficiently limited. However, the extra marginal profits of a socially responsible firm (obtained as the result of the trade-off between extra marginal revenues on each quantity unit of product sold and fraction of profits devoted to charity) are reduced when the number of competitors increases, impeding the diffusion of socially responsible companies. In particular, keeping constant the fraction of profits devoted to CSR activities, an increased number of competitors impacts on the trade-off between a higher net margin on sales obtained by socially responsible firms and a lower level of individual production that reduces the profit gap among firms of different types. By increasing the size of the oligopoly this trade-off modifies in such a way that mixed oligopolies emerge and are more likely. Moreover, when imposing the hypothesis of neutrality of CSR activities, according to which the competitive advantage of being a socially responsible company is offset by the higher costs associated with social activities, see in particular Williams et al. (2006) and Piga (2002), the model reveals that being socially responsible is an evolutionarily stable strategy for firms and is convenient for customers.

The benchmark model is confronted with a setup that introduces forms of bounded rationality in the decision process of firms in the sense that firms follow a so-called partial-adjustment-towards-the-best-response process, see Bischi et al. (2010), to determine the output to produce instead of coordinating to play the Bayesian-Cournot Nash equilibrium. The investigation of the dynamics of this model reveals the robustness of the results. In fact, introducing the described form of bounded rationality, analytical results show that the equilibria of the model are the same. Nevertheless, numerical experiments suggest that an heterogeneous population of firms representing an equilibrium configuration tends to lose stability when the frequency with which firms update their beliefs increases and to have the same stability property as in the benchmark model when the frequency of belief updating decreases. A plausible economic explanation for this phenomenon is related to the fact that reducing the frequency of belief updating, then the partial-adjustment-towards-the-best-response process has more time to converge toward the Nash strategy.

Summarizing, the current investigation adds to the literature on CSR activities by questioning the sustainability (Darwinian-like survival) of socially responsible companies, while the majority of contributions on this field focuses on the optimal level of CSR activities when government subsidies for being socially responsible are present; see, e.g., Arya and Mittendorf (2015). Specifically, showing that socially responsible companies can survive when supported by socially responsible consumers that are willing to pay more for their products may reduce the attention on government subsidies and their sustainability for public finances. Moreover, it may spark interest in the market conditions that favor the diffusions of socially responsible practices.

The paper is organized as follows. Section 2 describes the static setup. Section 3 introduces a hybrid evolutionary version of the model characterized by firms that 
behave as Nash players and by an updating mechanism of belief about the composition of the industry. In Sect. 4, the hypothesis of Nash players is relaxed and firms determine their output according to a partial-adjustment-towards-the-best-response process. Section 5 concludes. The analytical results are in "Appendix A."

\section{The setup of the oligopoly model}

Consider an industry populated by two types of firms, a firm which is only profitoriented, denoted by $P$, and a so-called socially responsible company, denoted by $N$. Despite the different attitude toward social aspects and the possibly different costs of production, the firms are homogeneous in all the other aspects, such as type of commodity produced and so on. Specifically, a firm of type $P$ produces at each period of time $t$ the level of output $q_{P, t}$ that maximizes its current profit $\pi_{P}\left(q_{P, t}, q_{-P, t}\right)$, where $q_{-P, t}$ is the level of production of its competitors. On the contrary, at each period of time $t$ a firm of type $N$ allocates a fraction $1-\theta$, with $\theta \in[0,1)$, of its current profits for social projects (such as charitable donations, CSR activities aimed to reduce environmental and social risks, effort spent on CSR disclosure $)^{4}$ and produces the level of output $q_{N, t}$ that maximizes its net profit (total profit reduced by the money earmarked for charity or CSR activities) $V_{N}\left(q_{N, t}, q_{-N, t}\right)=\theta \pi_{N}\left(q_{N, t}, q_{-N, t}\right)$, where $q_{-N, t}$ is the level of production of its competitors. Note that the optimal level of production $q_{N, t}$ is independent of the money earmarked for CSR activities, that is, it is independent of $\theta$.

The total production is sold in a market where customers discriminate between an output produced by a socially responsible firm and the one produced by a nonsocially responsible firm. Specifically, the demand side of the market is assumed as in Manasakis et al. (2014), in which, starting from Häckner (2000), consumers have identical preferences with respect to the physical characteristics of the goods but heterogeneous preferences on the CSR activities of the firms. Thus, the (inverse) demand functions are given by:

$$
P_{P}(Q)=\max \{0,1-\gamma Q\}
$$

and

$$
P_{N}(Q)=\max \{0, \alpha-\gamma Q\}
$$

\footnotetext{
${ }^{4}$ Here, charity and, more generally, CSR activities and strategies of CSR disclosure are proxied by a fraction of profits devoted to social projects. In the real cases, these types of investments (such as funds devoted to investments in environmentally friendly technologies or earmarked to mitigate the environmental and social risks of a company) are often accounted as fixed costs to be recognized in the financial statements instead of being accounted as fraction of profit set aside for social projects. Specifically, they can be a huge amount of money accounted as investments used to cut down profits and take advantage of tax breaks. Therefore, it makes sense to consider even large fractions of profits devoted to charity or to CSR activities while the extreme case $\theta=0$ is discussed for the sake of completeness. It is worth noting that these investments in charity or in CSR activities must be commensurate with profit levels in order to ensure financial sustainability, which is the reason why they are accounted as fraction of profits in our stylized modeling framework.
} 
for a firm of type $P$ and a firm of type $N$, respectively, where $Q$ is the aggregate production of the industry. Here $\alpha \geq 1$, where $\alpha-1$ is the extra reservation price that consumers are willing to pay to buy goods produced by socially responsible companies. ${ }^{5}$ Therefore, $\alpha-1$ measures the consumer preferences for CSR activities. A reader may wonder why, instead of paying an extra for products delivered by socially responsible companies, a consumer does not make directly a donation to charitable associations or to non-profit organizations that fight environmental and social risks. However, a small donation made through a surcharge may represent a small acceptable sacrifice for a consumer. The same consumer would hardly proceed to donate the same amount independently, because of the possible difficulties associated with this operation which instead are entirely addressed by the company through its CSR actions.

Concerning the production costs, they are assumed linear. Specifically, for a firm of type $P$ the cost of producing $q$ units of output is given by $C_{P}(q)=c_{P} q$, where $c_{P}$ is a positive real parameter, whereas for a firm of type $N$ the cost of producing $q$ units of output is given by $C_{N}(q)=c_{N} q$, where $c_{N}$ is a positive real parameter. A socially responsible firm may be characterized by a higher marginal cost, that is $c_{N} \geq c_{P}$. The higher marginal cost represents the extra burden for unit of output that a CSR activity entails.

Socially responsible activities may be profitable when consumers have a higher propensity to buy products sold by socially responsible firms. Specifically, in the current modeling setup, the following parameter restriction is a necessary condition to have the socially responsible strategy more profitable than the non-socially responsible strategy.

Assumption 1 The restriction $\alpha-c_{N}>1-c_{P}$ holds.

The condition imposed in Assumption 1 means that the reservation price reduced by the marginal cost of production for a socially responsible firm is larger than the reservation price reduced by the marginal cost of production of a non-socially responsible firm. This restriction of the parameter space establishes the trade-off that a socially responsible company faces, that is on the one hand this company enjoys an extra return on sales but on the other hand gives up a fraction of its own profits. The trade-off is based on a higher propensity to pay for products released by socially responsible firms, which requires that customers are aware of the socially responsible attitude of the firm that produces the product. This information is conveyed to customers through marketing policies. To promote, or communicate, the socially responsible attitude of the firm that produced a product, a labeling strategy is usually adopted, see for example, Testa et al. (2015), Lamantia and Radi (2015) and Gosselt et al. (2017).

Regarding the production side, consider an industry made of $n$ firms and assume that competitors of the same kind produce the same level of output. Then, given $k$ $P$-firms, the profit realized by a generic $P$-firm is

$$
\pi_{P}\left(q_{P}, q_{-P}\left(\bar{q}_{P}, \bar{q}_{N}, k\right)\right)=P_{P}\left(q_{P}+q_{-P}\left(\bar{q}_{P}, \bar{q}_{N}, k\right)\right) q_{P}-C_{P}\left(q_{P}\right)
$$

\footnotetext{
5 For the sake of completeness, the parameter restrictions do not exclude the case of limited practical interest represented by a high propensity to pay for products produced by CSR firms despite the profits set aside for CSR activities are almost null, that is the case $\theta \rightarrow 1$ and $\alpha$ much larger than one.
} 
where $q_{P}$ is the production by the representative $P$-firm while $q_{-P}\left(\bar{q}_{P}, \bar{q}_{N}, k\right)=$ $(k-1) \bar{q}_{P}+(n-k) \bar{q}_{N}$ is the production of the remainder of the industry with $\bar{q}_{P}$ which is the production by a single $P$-firm (excluding the one to which the profit refers to) and $\bar{q}_{N}$ which is the production by a single $N$-firm. Similarly, given $k P$-firms, the objective function for a representative $N$-firm is given by

$$
\begin{aligned}
V_{N}\left(q_{N}, q_{-N}\left(\bar{q}_{P}, \bar{q}_{N}, k\right)\right) & =\theta \pi_{N}\left(q_{N}, q_{-N}\left(\bar{q}_{P}, \bar{q}_{N}, k\right)\right) \\
& =\theta\left(P_{N}\left(q_{N}+q_{-N}\left(\bar{q}_{P}, \bar{q}_{N}, k\right)\right) q_{N}-C_{N}\left(q_{N}\right)\right)
\end{aligned}
$$

where $q_{-N}\left(\bar{q}_{P}, \bar{q}_{N}, k\right)=\left[k \bar{q}_{P}+(n-k-1) \bar{q}_{N}\right]$.

The socially responsible attitude of a company needs, indeed, to be communicated to the market to inform customers, and as discussed above, this is usually done through suitable marketing policies such as labeling strategies or advertising campaigns, the so called CSR disclosure. ${ }^{6}$ Therefore, each company can easily recognize the composition of the industry, in particular if a competitor behaves as socially responsible firm or not. However, this is an information available only ex post, that is after the level of production is decided and the output is obtained. Indeed, only when goods reach the market, a firm reveals to customers its socially responsible attitude. The socially responsible attitude shown in the past is not informative of the present behavior as a firm is always free to reconsider its socially responsible attitudes. Thus, firms take decisions about the level of production without knowing the identity, or socially responsible strategy, of their competitors. Despite that firms do not know the exact market competition they are going to face, they estimate the probability that a competitor is a firm of type P. Such a probability is denoted by $r$. Specifically, the number $k$ of firms type $P$ among the set of the $n-1$ competitors is a binomial random variable of parameter $r$, i.e., $\mathbb{P}(k)=\left(\begin{array}{c}n-1 \\ k\end{array}\right) r^{k}(1-r)^{n-k}$ where $k \in\{0,1, \ldots, n-1\}$.

Then, given the probability to have $k$ firms of type $P$ among the set of competitors and given the production of the remainder of the industry, a $P$-firm aims at maximizing its expected payoff, which is given by ${ }^{7}$

$$
\begin{aligned}
& \pi_{P}^{e}\left(q_{P}, q_{-P}\left(\bar{q}_{P}, \bar{q}_{N}, r\right)\right)=\mathbb{E}\left[\pi_{P}\left(q_{P}, q_{-P}\left(\bar{q}_{P}, \bar{q}_{N}, k\right)\right)\right] \\
& =\sum_{k=0}^{n-1}\left(\begin{array}{c}
n-1 \\
k
\end{array}\right) r^{k}(1-r)^{n-k-1} \pi_{P}\left(q_{P}, q_{-P}\left(\bar{q}_{P}, \bar{q}_{N}, k+1\right)\right)
\end{aligned}
$$

\footnotetext{
6 The modeling framework proposed in this paper is quite general and the fraction of profits devoted to CSR activities can also be interpreted as investments in persuasive advertising that aim to make costumers pay more for a product. However, since marketing activities are aimed to modify the perception of a product by customers, their effect on the willingness to pay of consumers should be endogenous while in the current setup it is exogenous. Moreover, persuasive advertising is always based on some sort of vertical differentiation of the products, which is not present in the current setup, and models devoted to study persuasive advertising are more focused on attracting market shares, see, e.g., the setup in Jiang and Srinivasan (2016). Therefore, we believe that the current setup is more suitable for studying the diffusion of socially-responsible attitudes and needs to be tailored in order to be used to study the diffusion of persuasive advertising.

7 The dependence of variables, such as the level of production, to $t$ is dropped here for the sake of notational simplicity. The dependence to $t$ will be introduced back in the next section.
} 
At the same time, an $N$-firm aims at maximizing its expected payoff, which is given by $V_{N}^{e}\left(q_{N}, r\right)=\theta \pi_{N}^{e}\left(q_{N}, r\right)$, where

$$
\begin{array}{r}
\pi_{N}^{e}\left(q_{N}, q_{-N}\left(\bar{q}_{P}, \bar{q}_{N}, r\right)\right)=\mathbb{E}\left[\pi_{N}\left(q_{N}, q_{-N}\left(\bar{q}_{P}, \bar{q}_{N}, k\right)\right)\right] \\
=\sum_{k=0}^{n-1}\left(\begin{array}{c}
n-1 \\
k
\end{array}\right) r^{k}(1-r)^{n-k-1} \pi_{N}\left(q_{N}, q_{-N}\left(\bar{q}_{P}, \bar{q}_{N}, k\right)\right)
\end{array}
$$

Consider the action space (the set of all the levels of production of each firm) to be limited to the set $A=[0, \bar{q}]$, where $\bar{q}$ is such that $p_{P}(n \bar{q})>0$, that is $\bar{q}=\frac{1}{n \gamma}$. Note that $p_{P}(n \bar{q})>0$ implies $p_{N}(n \bar{q})>0$. Then in $A$, due to the linearity of $\pi_{P}\left(q_{P}, q_{-P}\left(\bar{q}_{P}, \bar{q}_{N}, k\right)\right)$ and $\pi_{N}\left(q_{N}, q_{-N}\left(\bar{q}_{P}, \bar{q}_{N}, k\right)\right)$ with respect to $k$, we have that the expected value of $\pi_{P}$ and $\pi_{N}$ can be rewritten, respectively, as it follows:

$$
\pi_{P}^{e}\left(q_{P}, q_{-P}\left(\bar{q}_{P}, \bar{q}_{N}, r\right)\right)=\left(1-\gamma q_{P}-\gamma q_{-P}\left(\bar{q}_{P}, \bar{q}_{N}, r\right)-c_{P}\right) q_{P}
$$

and

$$
\pi_{N}^{e}\left(q_{N}, q_{-N}\left(\bar{q}_{P}, \bar{q}_{N}, r\right)\right)=\left(\alpha-\gamma q_{N}-\gamma q_{-N}\left(\bar{q}_{P}, \bar{q}_{N}, r\right)-c_{N}\right) q_{N}
$$

with $q_{-P}\left(\bar{q}_{P}, \bar{q}_{N}, r\right)=q_{-N}\left(\bar{q}_{P}, \bar{q}_{N}, r\right)=(n-1)\left[r \bar{q}_{P}+(1-r) \bar{q}_{N}\right]$. Therefore, the best-reply function of a firm of type $P$ is given by

$$
\begin{aligned}
B R_{P}\left(q_{-P}\left(\bar{q}_{P}, \bar{q}_{N}, r\right)\right) & =\underset{q_{P} \in A}{\arg \max } \pi_{P}^{e}\left(q_{P}, q_{-P}\left(\bar{q}_{P}, \bar{q}_{N}, r\right)\right) \\
& =\frac{1-c_{P}}{2 \gamma}-\frac{1}{2} q_{-P}\left(\bar{q}_{P}, \bar{q}_{N}, r\right)
\end{aligned}
$$

while, noting that a maximizer of $V_{N}^{e}$ is also a maximizer of $\pi_{N}^{e}$ and vice versa, the best-reply function of a socially responsible firm is given by

$$
\begin{aligned}
B R_{N}\left(q_{-N}\left(\bar{q}_{P}, \bar{q}_{N}, r\right)\right) & =\underset{q_{N} \in A}{\arg \max } \pi_{N}^{e}\left(q_{N}, q_{-N}\left(\bar{q}_{P}, \bar{q}_{N}, r\right)\right) \\
& =\frac{\alpha-c_{N}}{2 \gamma}-\frac{1}{2} q_{-N}\left(\bar{q}_{P}, \bar{q}_{N}, r\right)
\end{aligned}
$$

where $q_{-P}\left(\bar{q}_{P}, \bar{q}_{N}, r\right)=q_{-N}\left(\bar{q}_{P}, \bar{q}_{N}, r\right)=(n-1)\left[r \bar{q}_{P}+(1-r) \bar{q}_{N}\right]$.

The one described is a Bayesian game, see Harsanyi (1973), and by further assuming within-group symmetric levels of production, that is $q_{P}=\bar{q}_{P}$ and $q_{N}=\bar{q}_{N}$, and solving $B R_{P}\left(q_{-P}\left(q_{P}, q_{N}, r\right)\right)=q_{P}$ and $B R_{N}\left(q_{-N}\left(q_{P}, q_{N}, r\right)\right)=q_{N}$, we obtain an equilibrium in beliefs known as the symmetric Bayesian-Cournot Nash equilibrium:

$$
\begin{aligned}
& \left(q_{P}^{*}(r), q_{N}^{*}(r)\right) \\
& \quad=\left(\frac{2\left(1-c_{p}\right)+(n-1)(1-r)\left(1-c_{p}-\left(\alpha-c_{N}\right)\right)}{2 \gamma(n+1)},\right.
\end{aligned}
$$




$$
\left.\frac{2\left(\alpha-c_{N}\right)+(n-1) r\left(\alpha-c_{N}-\left(1-c_{P}\right)\right)}{2 \gamma(n+1)}\right)
$$

provided that $\left(q_{P}^{*}, q_{N}^{*}\right) \in A \times A$.

As specified above, the level of production of an $N$-firm does not depend on the fraction of its own profit used to finance socially responsible activities or charity activity. However, exploiting the higher reservation price that consumers are willing to pay to buy products realized by socially responsible firms, see Assumption 1, an $N$-firm produces additional output compared to a non-socially responsible company, as specified in the following lemma.

Lemma 1 Given the parameter restriction in Assumption 1, we have that $q_{N}^{*}-q_{P}^{*}=$ $\frac{\alpha-c_{N}-\left(1-c_{P}\right)}{2 \gamma} \geq 0$, i.e. $N$-firms always produce more than $P$-firms (regardless of $\theta$ ).

Employing the results in Lemma 1, we have that

$$
q_{N}^{*} \leq \frac{1}{n \gamma} \Leftrightarrow\left(\alpha-c_{N}\right) \leq\left(1-c_{P}\right)+\frac{2+2 n c_{P}}{2 n+(n-1) n r}
$$

and

$$
q_{P}^{*} \geq 0 \Leftrightarrow\left(\alpha-c_{N}\right) \leq\left(1+\frac{2}{(n-1)(1-r)}\right)\left(1-c_{P}\right)
$$

ensure that $\left(q_{P}^{*}, q_{N}^{*}\right) \in A \times A$. This result is summarized in the following lemma.

Lemma 2 Consider the reservation price, reduced by the marginal cost of production, of a product sold by a firm of type $N$ to exceed for an amount less than $\xi=\min \left\{\frac{2+2 n c_{P}}{2 n+(n-1) n r} ; \frac{2\left(1-c_{P}\right)}{(n-1)(1-r)}\right\}$ the reservation price, reduced by the marginal cost of production, of a product sold by a firm of type $P$, then $\left(q_{P}^{*}(r), q_{N}^{*}(r)\right)$ in Eq. (11) is a symmetric Bayesian-Cournot Nash equilibrium of the oligopoly market.

Denoting by $\pi_{P}^{*}(r)$ and by $\pi_{N}^{*}(r)$ the expected profits (5) and (6), respectively, at the Bayesian-Cournot Nash equilibrium, we have that

$$
\pi_{P}^{*}(r)=\gamma\left(q_{P}^{*}(r)\right)^{2} \text { and } V_{N}^{*}(r)=\theta \pi_{N}^{*}(r)=\theta \gamma\left(q_{N}^{*}(r)\right)^{2}
$$

Define $F(r)=\pi_{P}^{*}(r)-\theta \pi_{N}^{*}(r)$. Then the expected payoffs at the symmetric Bayesian-Cournot Nash equilibrium of the two strategies $P$ and $N$ are equal when $F(r)=0$, which is the so-called iso-profit condition. Since $F(r)=0$ is a quadratic equation in $r$, there exist at most two probabilities $r_{1}^{*}$ and $r_{2}^{*}$ for which the profit of a non-socially responsible firm, a $P$-firm, and the profit of a socially responsible firm, an $N$-firm, are equal. Solving $F(r)=0$, we obtain

$$
r_{1,2}^{*}=\frac{2\left(\alpha-c_{N}\right)}{(n-1)\left(1-c_{P}-\alpha+c_{N}\right)}+\frac{(n+1)(1 \pm \sqrt{\theta})}{(1-\theta)(n-1)}
$$


In order to have that these two values represent probabilities for which the isoprofit condition is satisfied, the further condition $r_{1,2}^{*} \in[0,1]$ is required. Numerical evidence suggests that there are configurations of the parameter values for which both equilibria are feasible. This is confirmed by analytical arguments. Indeed, the values $r_{1}^{*}$ and $r_{2}^{*}$ in (15) can be rewritten in an equivalent way as it follows:

$$
r_{1,2}^{*}(\theta)=\frac{(n+1)\left(\alpha-c_{N}-1+c_{P}\right)-2(1 \mp \sqrt{\theta})\left(\alpha-c_{N}\right)}{(n-1)(1 \mp \sqrt{\theta})\left(\alpha-c_{N}-1+c_{P}\right)}
$$

It is clear that the solutions $r_{1,2}^{*}(\theta)$ are real and distinct for $\theta>0$ with $r_{1}^{*}(\theta)>r_{2}^{*}(\theta)$ and they are real and coincident for $\theta=0$. Specifically, for $\theta=0$ we have

$$
r_{1,2}^{*}(0)=1-\frac{2\left(1-c_{P}\right)}{(n-1)\left(\alpha-c_{N}-1+c_{P}\right)}
$$

Therefore, $r_{1,2}^{*}(0) \in(0,1)$ if and only if the following condition is satisfied

$$
\left(\alpha-c_{N}\right)>\frac{(n+1)}{(n-1)}\left(1-c_{P}\right)
$$

Specifically, when condition (18) is satisfied, it is obvious that $r_{1,2}^{*}(\theta) \in(0,1)$ for $\theta$ sufficiently close to zero.

The analysis so far conducted, as well as the one that follows, is devoted to providing a description of the behavior of the market under all possible configurations of the willingness to pay for products delivered by socially responsible firms, that is $\alpha$, and of the fraction of profits devoted to CSR activities. The aim is to describe the behavior of the market under all possible configurations of these two parameters, which are expected to be related in practice. Their relationship, together with a specific target, are the elements to employ for determining the optimal fraction of profits to devote to CSR activities. Here, consistently with the descriptive approach adopted, it is avoided the formulation of any arbitrary choice, or assumption, on how these parameters are related. However, estimating the relationship, which links $\alpha$ to CSR activities, by empirical techniques and having a goal to follow, the current analysis can suggest the optimal fraction of profit that firms devote to social projects and can suggest the optimal extra willingness to pay for products delivered by CSR firms.

\section{The probability of a socially responsible behavior when companies are Nash players}

In the previous section, we have analyzed a static setup in which the probability $r$ to meet a $P$-firm is given. Here, the setup is generalized to the case in which the value of $r$ is updated according to a classical evolutionary model. Specifically, at each instant of time firms produce the Nash quantities while at regular intervals of time $t \in\{s, 2 s, \ldots, m s, \ldots$,$\} , with m \in \mathbb{N}$, a firm revises its belief about the probability 
that a competitor is of type $P$ according to an evolutionary scheme based on the difference between average accrued profits over the past period $[t-s, t]$ for a nonsocially responsible firm and for a socially responsible firm, see, e.g., Bischi et al. (2015). Given $r_{t}$ the probability to meet a $P$-firm at time $t$, we further assume that firms, according to their type, coordinate at each period of time to play the BayesianCournot Nash equilibrium in (11). Then, employing the expected profits as a proxy for the realized profits, ${ }^{8}$ which is a modeling choice proposed in Droste et al. (2002), we have that the gap of the average profit between a $P$-firm and an $N$-firm over the period $[t, t+s]$ is given by

$$
\frac{\int_{t-s}^{t} \pi_{P}^{e}\left(q_{P}^{*}, q_{-P}\left(q_{P}^{*}, q_{N}^{*}, r_{t}\right)\right) \mathrm{d} \tau-\theta \int_{t-s}^{t} \pi_{N}^{e}\left(q_{N}^{*}, q_{-N}\left(q_{P}^{*}, q_{N}^{*}, r_{t}\right)\right) \mathrm{d} \tau}{s}
$$

which simplifies as in (14), i.e. it is equal to $F\left(r_{t}\right)=\pi_{P}^{*}\left(r_{t}\right)-\theta \pi_{N}^{*}\left(r_{t}\right)$. The setup of the model is completed by assuming that each firm updates its belief about $r$ at time $t+s$ according to the following difference equation:

$$
r_{t+s}=G\left(r_{t}\right) \quad \text { with } \quad G\left(r_{t}\right)=\frac{r_{t}}{r_{t}+\left(1-r_{t}\right) \mathrm{e}^{-\eta F\left(r_{t}\right)}}
$$

where $\eta \in[0,+\infty)$ is the intensity of choice, which measures how sensitive the players are at selecting a profit-increasing behavioral rule.

The function $G$ in (20) defines a so-called exponential replicator dynamics, see Hofbauer and Sigmund (2003). This setup has the advantage of strengthening the strategy that performs better, in contrast to updating beliefs of logit type or similar setups based on the discrete random utility theory; see McFadden (1980). It is also worth mentioning that the hybrid evolutionary model in (20) does not imply that a firm will stay committed to a given strategy for a period of time $s$, but rather that a firm revises its beliefs only at regular periods of time using the average profits obtained in the period. This modeling aspect finds several justifications, for example, information about the performances of firms are made available only at regular periods of time, for example, once a year when balance sheets of companies are published.

The parameter restrictions for the model in (20), which are summarized in the following, are the same as the ones for the static setup of the previous section, except for some parameters that are present only in the dynamic framework.

Assumption 2 The following parameter-value restrictions are considered for the model in (20):

1. Firms have a positive propensity to select the profit-increasing behavioral rule, that is $\eta \in(0,+\infty)$;

2. A fraction of the profit of an $N$-firm is devoted to CSR activities, that is $\theta \in[0,1)$;

\footnotetext{
8 As in Hommes et al. (2018), consider the oligopoly modeled as a population game. Specifically, consider a large population of firms from which groups of $n$ firms are sampled randomly at regular intervals of time $t \in\{s, 2 s, \ldots, m s, \ldots$,$\} , with m \in \mathbb{N}$, to play the Cournot oligopoly repeatedly in $[t-s, t]$. If the population of firms and the number of groups of $n$ firms drawn from that population are large enough, average profits will be approximated quite well by these expected profits.
} 
3. The industry is an oligopoly, that is $n \geq 2$ and $n \in \mathbb{N}$;

5. The reservation price for products produced by an $N$-firm is greater than the one for products produced by a $P$-firm, that is $\alpha \in(1,+\infty)$;

6. The slope of the inverse demand function is non-negative, that is $\gamma \in(0,+\infty)$;

7. The unitary cost of production of an $N$-firm is not lower than the one of a $P$-firm, that is $c_{N} \geq c_{P} \geq 0$;

8. The restriction $\alpha-c_{N}>1-c_{P}$ holds.

Considering the restrictions in Assumption 2, the global dynamics of the model as a function of the parameter $\theta$, that is the fraction of profit that an $N$-firm does not devoted to charity, is describe in the following Theorem, the proof of which is in "Appendix A."

\section{Theorem 1 Define}

$$
\begin{aligned}
\theta^{0} & =\frac{\left(2\left(1-c_{p}\right)+(n-1)\left(1-c_{P}-\alpha+c_{N}\right)\right)^{2}}{4\left(\alpha-c_{N}\right)^{2}}, \\
\theta^{1} & =\frac{4\left(1-c_{p}\right)^{2}}{\left(2\left(\alpha-c_{N}\right)+(n-1)\left(\alpha-c_{N}-1+c_{P}\right)\right)^{2}},
\end{aligned}
$$

$\underline{\theta}=\min \left\{\theta^{0}, \theta^{1}\right\}, \bar{\theta}=\max \left\{\theta^{0}, \theta^{1}\right\}, \theta^{F}$ such that $1+\eta \frac{\partial F}{\partial r}\left(r_{2}^{*}\left(\theta^{F}\right)\right)\left(1-r_{2}^{*}\left(\theta^{F}\right)\right) r_{2}^{*}$ $\left(\theta^{F}\right)=-1$ and denote by $\mathcal{B}(\cdot)$ the basin of attraction of the equilibrium $\cdot$. Consider the restrictions in Assumption 2, the global dynamics of the model defined in Eq. (20) is such that:

1. for $\theta \in[0, \underline{\theta}), \mathcal{B}(1)=(0,1]$ when condition (18) is satisfied, otherwise $\mathcal{B}(1) \supseteq$ $\left(r_{1}^{*}, 1\right]$ and $r_{2}^{*} \in(0,1)$ is either locally asymptotically stable or unstable;

2. for $\theta \in(\underline{\theta}, \bar{\theta})$ two alternatives are possible:

2a. when $\theta^{1}<\theta^{0}, r_{2}^{*}$ is locally asymptotically stable as long as $\theta<\theta^{F}$, otherwise an inner attractor (either periodic or chaotic) exists.

2b. when $\theta^{1}>\theta^{0}, \mathcal{B}(0)=\left[0, r_{1}^{*}\right)$ and $\mathcal{B}(1)=\left(r_{1}^{*}, 1\right]$.

3. for $\theta \in(\bar{\theta}, 1), \mathcal{B}(0)=[0,1)$;

Moreover, at $\theta=\theta^{0}$ (resp. $\left.\theta=\theta^{1}\right)$ the equilibrium 0 (resp. 1$)$ undergoes a transcritical bifurcation. At $\theta=\theta_{1}=\theta_{0}$ the interval $[0,1]$ is filled with equilibria, each of which is marginally stable. The inner equilibrium $r_{2}^{*}$ loses stability through a flip bifurcation at $\theta=\theta^{F}$.

The results in Theorem 1 underline the important aspect that the fraction $1-\theta$ of the profit, which a socially responsible firm devotes to CSR activities and charity, should be limited to the value $1-\bar{\theta}$ to have that the oligopoly is populated by only socially responsible firms. This threshold depends on the propensity gap of a representative consumer to pay for commodities produced by socially responsible firms. The bifurcation diagrams in Fig. 1 represent a specific configuration of the oligopoly market and show that the threshold decreases when the size of the industry increases, i.e., when 


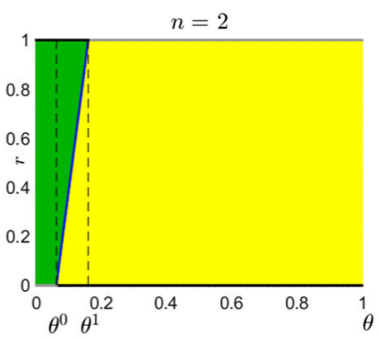

(a)

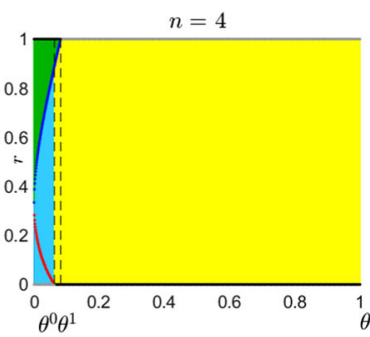

(b)

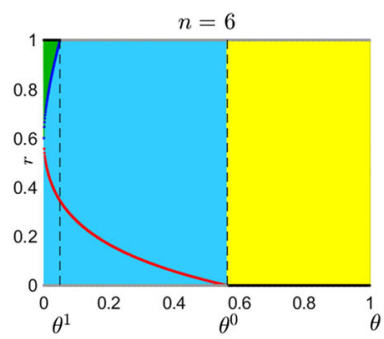

(c)

Fig. 1 Bifurcation diagrams with bifurcation parameter $\theta$ varying in $[0,1)$. The border equilibria 0 and 1 , at which all firms are socially responsible and non-socially responsible, respectively, are in black if stable and in gray if unstable. The inner equilibrium $r_{1}^{*}$ (resp. $r_{2}^{*}$ ) is represented by a blue (resp. red) curve as $\theta$ increases. For each value of $\theta$ in $[0,1)$, the basin of attraction of the equilibrium 1 is represented in green, in yellow that of the equilibrium 0 , and in azure the basin of the interior equilibrium $r_{2}^{*}$. The bifurcation value $\theta^{1}$ (transcritical bifurcation) for the equilibrium 1 is indicated by a black dashed line as well as the bifurcation value $\theta^{0}$ (transcritical bifurcation) for the equilibrium 0. Parameters: $\alpha=1.9, \gamma=0.01$, $c_{P}=0.1 ; c_{N}=0.1$ and $\eta=1$. Moreover, $n=2$ in panel (a), $n=4$ in panel (b) and, $n=6$ in panel (c) (colour figure online)

the number of competitors increases. This is due to the fact that a higher competition reduces the extra marginal profits that a socially responsible firm obtains. Specifically, when the extra productivity of a socially responsible firm shrinks because the competition increases, the threshold $1-\bar{\theta}$ may not exists. It is the case, for example, of the market represented by the bifurcation diagrams in Fig. 2. Here, we have a market configuration which is equal to the one represented in Fig. 1, with the only exception that the number of firms that populate the oligopoly market is larger. The increased competition reduces the marginal profits of every single firm and also the extra profit that a socially responsible firm obtains. Even in this contest of higher market competition, it is possible to observe that the number of socially responsible firms increases when the fraction of profits devoted to CSR activities decreases. However, differently to what happens in the cases of low levels of competition, the oligopoly converges to an equilibrium such that the probability to meet a non-socially responsible firm is always positive even when the fraction of profits earmarked for charity by a $P$-firm are very low, that is, $\theta$ is large.

The role played by the number of competitors on the composition of the oligopoly can be further explored through economic arguments. The gap of gross margins on sales between a socially responsible company and a company which is not socially responsible, that is $\gamma\left(q_{N}^{*}(r)-q_{P}^{*}(r)\right)$, is independent of the size of the oligopoly and of its composition. In fact, Lemma 1 specifies that $q_{N}^{*}(r)-q_{P}^{*}(r)=\frac{\alpha-c_{N}-\left(1-c_{P}\right)}{2 \gamma}$, which implies $\frac{\partial q_{N}^{*}(r)}{\partial n}=\frac{\partial q_{P}^{*}(r)}{\partial n}$. Moreover, $\theta \in[0,1)$ and the level of production of each type of company is negatively related to the size of the oligopoly. It follows that $\theta \frac{\partial q_{N}^{*}(r)}{\partial n}>\frac{\partial q_{P}^{*}(r)}{\partial n}$, which implies that the gap of the net marginal revenues $\gamma\left(\theta q_{N}^{*}(r)-q_{P}^{*}(r)\right)$ is increasing with respect to the size of the oligopoly. This may suggest that increasing the size of the oligopoly the fraction of socially responsible companies is also expected to increase. However, the level of production of every sin- 


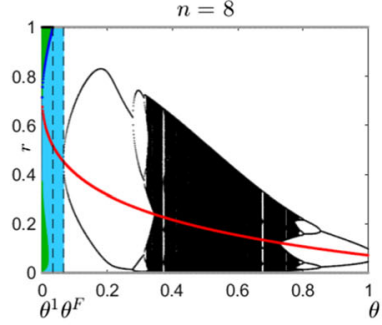

(a)

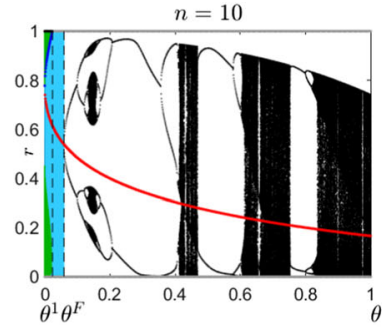

(b)

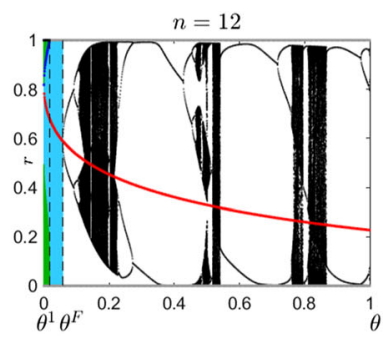

(c)

Fig. 2 Bifurcation diagrams with bifurcation parameter $\theta$ varying in $[0,1)$. The border equilibria 0 and 1 , at which all firms are socially responsible and non-socially responsible, respectively, are in black if stable and in gray if unstable. The inner equilibrium $r_{1}^{*}$ (resp. $r_{2}^{*}$ ) is represented by a blue (resp. red) curve as $\theta$ increases. For each value of $\theta$ in $[0,1)$, the basin of attraction of the equilibrium 1 is represented in green, in yellow that of the equilibrium 0 , in azure the basin of the interior equilibrium (red curve) and in white the basin of attraction of the inner periodic or chaotic attractor. The bifurcation value $\theta^{1}$ (transcritical bifurcation) for the equilibrium 1 is indicated by a black dashed line as well as the bifurcation value $\theta^{F}$ (flip bifurcation) for the inner equilibrium. Parameters: $\alpha=1.9, \gamma=0.01, c_{P}=0.1 ; c_{N}=0.1$ and $\eta=1$. Moreover, $n=8$ in panel (a), $n=10$ in panel (b) and, $n=12$ in panel (c). The value of $\theta^{F}$ is detected numerically (colour figure online)

gle company decreases when the size of the oligopoly increases and this second effect can offset the higher gap of net margins on sales and reduce the speed of diffusion of socially responsible companies as a consequence of a lower profit gap between socially responsible companies and non-socially responsible companies. This is the trade-off that a firm which pursues a social cause faces, which determines the composition of the oligopoly.

Numerical observations suggest that for small $\theta$ the first effect prevails when the size of the oligopoly increases and the trade-off becomes more favorable to socially responsible firms. See Fig. 3a, where we observe that in an oligopoly composed mainly of $P$-firms the extra profit of a socially responsible firm increases when the size of the oligopoly increases from two to six. The opposite occurs when $\theta$ is large. See Fig. 4a, where we observe that the extra profit of a socially responsible firm decreases when the size of the oligopoly increases from two to six and this happens independently of the composition of the industry. Analytical arguments indicate that this numerical observation depends on the gap between $\theta \frac{\partial q_{N}^{*}(r)}{\partial n}$ and $\frac{\partial q_{P}^{*}(r)}{\partial n}$, which expands when $\theta$ reduces. Therefore, more socially responsible firms are expected when the size of the oligopoly increases and the fraction of profits devoted to CSR activities is large, while a reduction of the presence of socially responsible firms is expected when the size of the oligopoly increases and the fraction of profits devoted to CSR activities is smaller. Noting that for large values of the fraction of profits devoted to CSR activities the oligopoly is expected to be populated by non socially responsible firms and vice versa in the opposite case, see Theorem 1, we can say that an increase of the size of the industry favors a mixed oligopoly where socially responsible firms and non-socially responsible firms coexist. This phenomenon is confirmed by the numerical simulations and bifurcation diagrams in Figs. 1 and 2. 


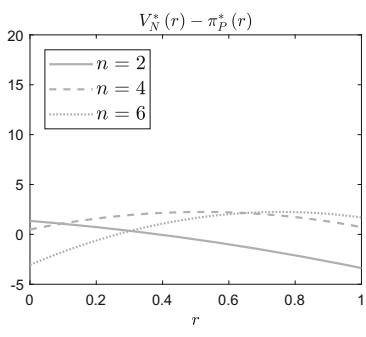

(a)

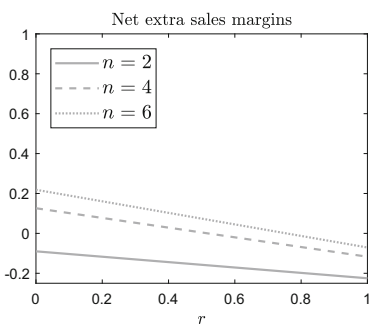

(b)

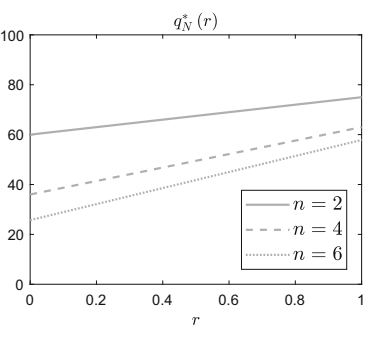

(c)

Fig. 3 Parameters: $\alpha=1.9, \gamma=0.01, c_{P}=0.1, c_{N}=0.1$ and $\theta=0.1$. In panel $\mathbf{b}$ the net extra sales margins are defined as $\gamma\left(\theta q_{N}^{*}(r)-q_{P}^{*}(r)\right)$

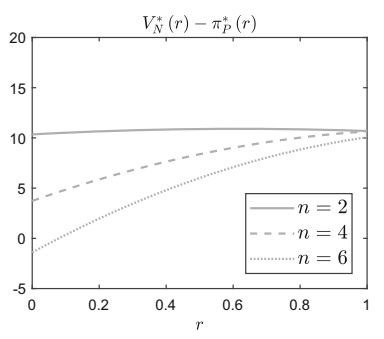

(a)

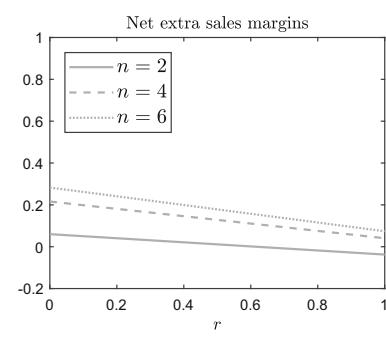

(b)

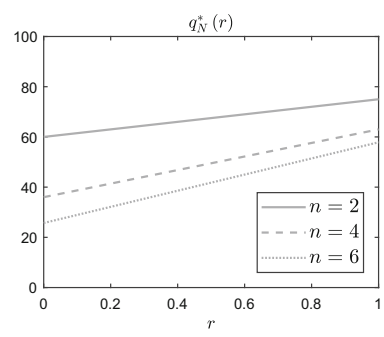

(c)

Fig. 4 Parameters: $\alpha=1.9, \gamma=0.01, c_{P}=0.1, c_{N}=0.1$ and $\theta=0.35$. In panel $\mathbf{b}$ the net extra sales margins are defined as $\gamma\left(\theta q_{N}^{*}(r)-q_{P}^{*}(r)\right)$

A further aspect on which we intend to investigate with this work concerns the hypothesis of neutrality of CSR activities, according to which the competitive advantage they bring is however offset by the higher costs associated with social activities, see in particular Williams et al. (2006) and Piga (2002). Here the aim is to investigate the hypothesis of neutrality of CSR activities in an evolutionary framework. In fact, assuming the hypothesis of neutrality of CSR activities, a relevant aspect regards the attractiveness of the socially responsible strategy. Obviously the hypothesis of neutrality of CSR activities cannot be guaranteed whatever the composition of industry, specifically whatever is the probability to meet a $P$-firm. Therefore, we question the evolutionary attractiveness of the socially responsible strategy when the hypothesis of neutrality of CSR activities is satisfied for an industry homogeneously populated by either $P$-firms or $N$-firms. In this case, the common wisdom may suggest that the CSR strategy is not adopted by firms. Indeed, why should the industry adopt a strategy that will not provide any economic advantage? Despite this observation at the industry level, the following Lemma, the proof of which is in "Appendix A," indicates that when the hypothesis of neutrality of CSR activities is satisfied, all the firms will adopt in the long run the CSR strategy.

Lemma 3 Consider the hypothesis of neutrality of CSR activities: $F(1)=F(0)=0$, where $F\left(r_{t}\right)=\pi_{P}^{*}\left(r_{t}\right)-\theta \pi_{N}^{*}\left(r_{t}\right)$ as in $(19)$. Then, $\mathcal{B}(0)=[0,1), q_{N}^{*}(0)>q_{P}^{*}(1)$ and $\pi_{P}^{*}(1)>\theta \pi_{N}^{*}(0)$. 
The results in Lemma 3 also specify that an industry homogeneously populated by socially responsible firms is not only an evolutionarily stable equilibrium, but it is also a market configuration where firms produce a larger output. This occurs because the socially responsible strategy impacts on the level of competition. Specifically, it increases the demand for the output. Moreover, despite being an evolutionarily stable strategy, the net profit of a firm in an industry homogeneously populated by socially responsible companies is lower than the net profit the same firm would obtain in an industry homogeneously populated by non-socially responsible companies.

Consider, moreover, the case in which consumers, instead of paying more for outputs produced by socially responsible firms, devote their money to charity directly. This would have the same effect in terms of money devoted to charity, but the level of profit of every single firm would be higher and their level of production would be lower. Therefore the pool of customers that each company reaches with its product will be smaller and a consumer will spend more to buy the same product and to devote the same amount of money to CSR activities. It follows that, under the hypothesis of neutrality of CSR activities, for a customer it is rational to pay an extra amount for products realized by socially responsible firms while being socially responsible is an evolutionarily stable strategy and a Bayesian-Cournot Nash equilibrium.

The discussed aspects underline that the hypotheses in Lemma 3 identify an equilibrium represented by an oligopoly populated by socially responsible firms which is evolutionarily stable and Pareto-dominated at the same time, therefore a sort of prisoner dilemma. This configuration occurs even when the hypothesis of neutrality of CSR activities is relaxed. Consider for example the configuration of parameters of Fig. 1, panel (a). The graphical representation of the profits shows that being a socially responsible firm is not profitable despite an oligopoly populated by socially responsible firms is evolutionarily stable. In fact, being in an oligopoly of firms that are not socially responsible is more profitable, see Fig. 5, panels (a) and (b), where $\pi_{P}^{*}(1)>V_{N}^{*}(0)$. At the same time, an evolutionarily stable oligopoly of socially responsible firms may be as profitable as an oligopoly of firms which are not socially responsible, see Fig. 5, panels (c) and (d), where $V_{N}^{*}(0)=\pi_{P}^{*}(1)$. Finally, an oligopoly of socially responsible firms can be both more profitable and evolutionarily stable, therefore a Pareto-dominant equilibrium, see Fig. 5, panels (e) and (f), where $V_{N}^{*}(0)>\pi_{P}^{*}(1)$.

The presence of both Pareto-dominated and Pareto-dominant (from the point of view of firms' profits) equilibria that are evolutionarily stable is consistent with the ambiguous relationship between CSR actions and firm performances which is supported by empirical evidence. Specifically, a negative relationship between CSR attitudes and financial performances are observed in Marcus (1989) and in Vance (1975). Whereas, a positive relationship is found in Belkaoui (1976), in Hart and Ahuja (1996) and in Riahi-Belkaoui (1992). Moreover, some have observed an inconclusive relationship, see, e.g., Aupperle et al. (1985) and in Dahlsrud (2008). 


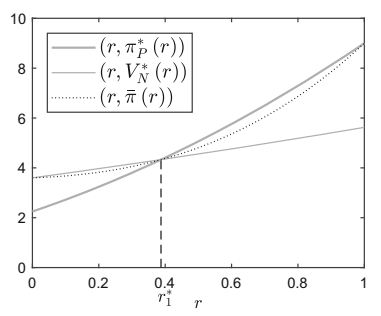

(a)

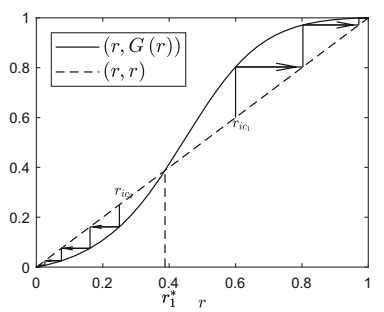

(b)

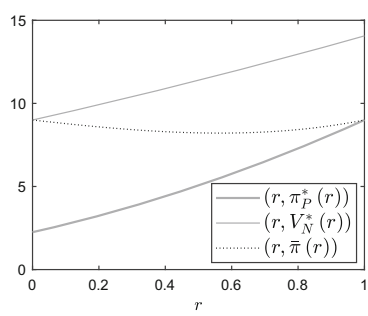

(c)

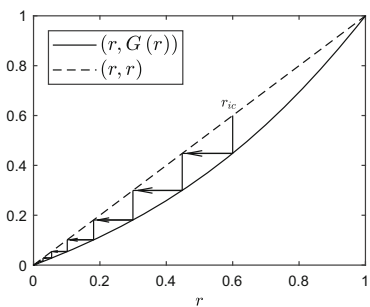

(d)

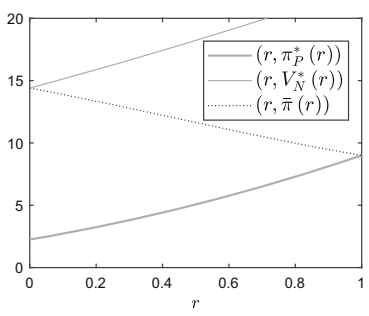

(e)

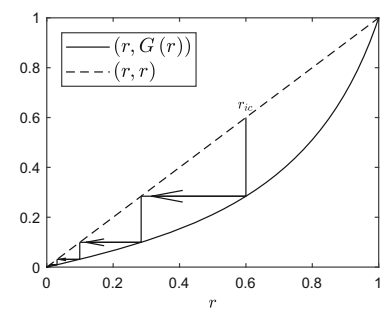

(f)

Fig. 5 In panels a, $\mathbf{c}$ and $\mathbf{d}$ graphical representation of the profits $\pi_{P}^{*}(r)$, defined in (14), $V_{N}^{*}(r)$ defined as in (14), and $\bar{\pi}(r)=r \pi_{P}^{*}(r)+(1-r) V_{N}^{*}(r)$. In panels $\mathbf{b}, \mathbf{d}$ and $\mathbf{f}$, graph of the function $G$ that defines the dynamical system in (20) and staircase diagrams showing some trajectories are depicted. The parameters are as in Fig. 1, panel a, that is: $\alpha=1.9, \gamma=0.01, c_{P}=0.1 ; c_{N}=0.1$ and $n=2$. Moreover, $\eta=1$ and $\theta=0.1$ in panels $\mathbf{a}$ and $\mathbf{b}, \eta=0.1$ and $\theta=0.25$ in panels $\mathbf{c}$ and $\mathbf{d}$ and, $\eta=0.1$ and $\theta=0.4$ in panels $\mathbf{e}$ and $\mathbf{f}$. The value of $\eta$ in panels $\mathbf{c}-\mathbf{f}$ is set equal to 0.1 , instead of 1 , to better show the staircase diagrams

\section{The probability of a socially responsible behavior when companies are boundedly rational}

The setup considered in the previous section is based on the assumption that companies are Nash players, that is at each period of time and independently of their attitude toward social responsibility they coordinate to play the Bayesian-Cournot Nash equilibrium of the oligopoly game. However, in most cases, this type of rationality may not be guaranteed for several reasons. Here we want to test the robustness of the results obtained in the previous section by relaxing the assumption of Nash players. Specifically, as assumed in the previous section, firms revise their beliefs about the probability to meet a non-socially responsible firm only at regular intervals of time of length $s$. Moreover, firms take their production decision according to the so-called partial adjustment towards the best response with naive expectations, see Bischi et al. (2010). This is a behavioral rule such that at each instant of time the output level of a firm is selected somewhere in between the previous level of production and the quantity of best response, the latter one computed assuming constant the production of the competitors. Therefore, firms are assumed to be boundedly rational as they do not set their production at the level that maximizes their profits. Under the further assumption that the firms have the same degree of rationality and thus firms of the same type produce the same level of output, the quantity dynamics that describe the partial adjustment dynamics towards the best response with naive expectations is represented 
by the following system of two ordinary differential equations:

$$
\left\{\begin{array}{l}
\dot{q}_{P, t}=\phi\left(B R_{P}\left(q_{P, t}, q_{-P}\left(q_{P, t}, q_{N, t}, r_{\left\lfloor\frac{t}{s}\right\rfloor s}\right)\right)-q_{P, t}\right) \\
\dot{q}_{N, t}=\phi\left(B R_{N}\left(q_{N, t}, q_{-N}\left(q_{P, t}, q_{N, t}, r_{\left\lfloor\frac{t}{s}\right\rfloor s}\right)\right)-q_{N, t}\right)
\end{array}\right.
$$

where $B R_{P}$ and $B R_{N}$ are the best-reply functions defined in (9) and (10), respectively, and $\phi>0$ is a speed of adjustment towards the level of production that represents the best response strategy to the expected level of production of the rest of the industry. As specified, a firm revises its belief about the probability $r$ to meet a $P$-firm only at regular periods of time of length $s$, which is therefore a positive real parameter of the model, see, e.g. Bischi et al. (2013a, b) and Lamantia and Radi (2015). Therefore,

$$
r_{t}= \begin{cases}\frac{r_{t-s}}{r_{t-s}+\left(1-r_{t-s}\right) \mathrm{e}^{\eta\left(\bar{\pi}_{N, t}-\bar{\pi} P, t\right)}} & \text { if } t=\left\lfloor\frac{t}{s}\right\rfloor s \\ r_{\left\lfloor\frac{t}{s}\right\rfloor s} & \text { otherwise }\end{cases}
$$

where $\bar{\pi}_{i, t}$, with $i=P, N$, is the average expected profit obtainable by a $i$-firm over the period $[t-s, t]$. Specifically,

$$
\begin{aligned}
& \bar{\pi}_{P, t}=\frac{\int_{t-s}^{t} \pi_{P}^{e}\left(q_{P, \tau}, q_{-P}\left(q_{P, \tau}, q_{N, \tau}, r_{t-s}\right)\right) \mathrm{d} \tau}{s} \text { and } \\
& \bar{\pi}_{N, t}=\frac{\theta \int_{t-s}^{t} \pi_{N}^{e}\left(q_{N, \tau}, q_{-N}\left(q_{P, \tau}, q_{N, \tau}, r_{t-s}\right)\right) \mathrm{d} \tau}{s}
\end{aligned}
$$

with functions $\pi_{P}^{e}$ and $\pi_{N}^{e}$ defined as in (7) and (8), respectively.

The dynamical system obtained by coupling (22) with (23) is a hybrid dynamical system, which describes the evolution of the composition of the oligopoly market and the level of production of the industry and of its representative firms. The model in (22)-(23) generalizes the hybrid evolutionary game in (20) by introducing a form of rationality in the production decision process of the firms. Considering the restrictions in Assumption 2, as specified in the following Theorem, the proof of which is in "Appendix A", the equilibria of the model as a function of the parameter $\theta$ are the same ones as for the model with Nash players in (20).

Theorem 2 Assuming the same values of the parameters, $\left(q_{P}^{*}\left(r^{*}\right), q_{N}^{*}\left(r^{*}\right), r^{*}\right)$, with $q_{N}^{*}\left(r^{*}\right)$ and $q_{N}^{*}\left(r^{*}\right)$ as in (11), is an equilibrium of the model in (22)-(23) if and only if $r^{*}$ is an equilibrium of the model in (20). Further equilibria of the model in (22)-(23) do not exist.

The analytical results of Theorem 2 indicate that the bounded rationality introduced with model (22)-(23) does not impact the equilibria of the system, which remain the same. However, the stability and the global dynamics of the model may be affected by the form of bounded rationality introduced. Considering the constellation of the values of the parameters as in Fig. 1, we observe that the global dynamics of the model with 
boundedly-rational firms defined in (22)-(23) is similar to the one of the model with Nash players defined in (20). Compare the basins of attraction represented as a function of $\theta$ for model (20) in Fig. 1 and the basins of attraction represented as a function of $\theta$ for model (22)-(23) in Fig. 6, which are obtained for the same constellation of the values of the parameters. The comparison indicates that the global dynamics is very similar. The only exception regards the stability of the inner equilibrium. Specifically, we observe that the stability of the inner equilibrium is affected by the parameter $s$, which represents the length of the time interval over which the beliefs about the composition of the industry are kept constant. Consider $s=3$. We observe that for an industry populated by six firms and $\theta \in\left[\theta^{1}, \theta^{0}\right]$, the inner equilibrium of the model (20) with Nash players is stable while the dynamics of the model with boundedlyrational firms is characterized by stable two cycles. Reducing the value of $s$, see Fig. 7, we observe what a numerical analysis suggests to be a sequence of perioddoubling bifurcations as $\theta$ increases, which gives rise to cycles of periodicity even higher than two or, eventually, to a chaotic attractor. The sequence of period-doubling bifurcations is followed by what a numerical investigation suggests to be a sequence of period halving bifurcations through which an inner equilibrium becomes stable before vanishing through a transcritical bifurcation at $\theta=\theta^{1}$. Thus, the model with boundedly rational firms is characterized by periodic cycles instead of a stable Bayesian-Cournot Nash equilibrium and this depends, of course, on the lower coordination capability of the boundedly rational firms. If this observation may appear obvious, less intuitive is the observation that a reduction of the frequency with which players update their beliefs about the composition of the industry may have a stabilizing effect, favoring the coordination of the players towards the Bayesian-Cournot Nash equilibrium. In particular, we observe that for $s \rightarrow+\infty$ we have a gain of stability of the BayesianCournot Nash equilibrium, see Fig. 8 obtained for $s=10$. A possible interpretation of this fact is the following: A reduction of the updating frequency of the beliefs favors the coordination of the firms towards the Nash levels of production between two consecutive times at which beliefs are updated. Specifically, it increases the time available to the output dynamics in (22) to converge towards a Bayesian-Cournot Nash equilibrium, which on its own favors the equilibrium in beliefs.

An increase of the level of competition, obtained by augmenting the number of firms in the industry, destabilizes also the Bayesian-Cournot Nash equilibrium of model with Nash players defined in (20). As already discussed, numerical observations, see Fig. 2 , suggest that a sequence of period-doubling bifurcations gives rise to stable cycles of period 2 or higher, eventually to chaotic dynamics when the fraction of the profit of a $P$-firm devoted to charity decreases. Introducing boundedly rational firms in the form of a partial adjustment dynamics toward the best response with naive expectations as in (22), and assuming that firms update their belief about the composition of the industry after periods of length $s=3$, as in (23), we observe that the inner BayesianCournot Nash equilibrium, the red curve in Fig. 9, loses stability at higher values of the fraction of profits devoted to charity and periodic or chaotic attractors arise. An increase of the length of the periods after which beliefs are updated allows to converge towards long-run dynamics similar to the one of the model without boundedly rational players, compare Fig. 10, obtained for $s=10$, with Fig. 2. The latter numerical observations confirm, therefore, that reducing the frequency of belief updating can 


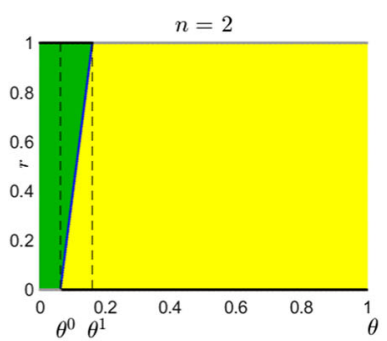

(a)

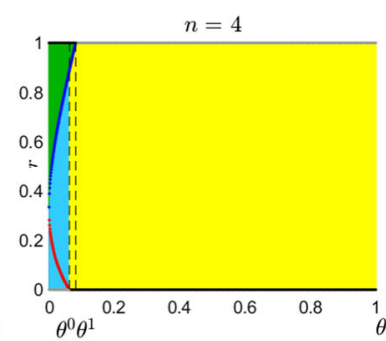

(b)

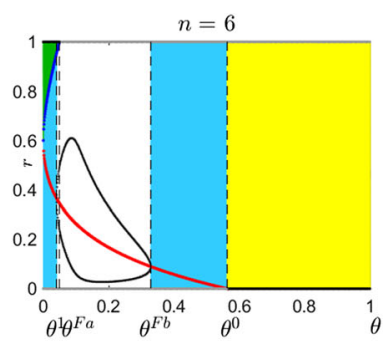

(c)

Fig. 6 Global dynamics of the hybrid model (22)-(23). Bifurcation diagrams with bifurcation parameter $\theta$ varying in $[0,1)$. The border equilibria $\left(q_{P}^{*}(0), q_{N}^{*}(0), 0\right)$ and $\left(q_{P}^{*}(1), q_{N}^{*}(1), 1\right)$, at which all firms are socially responsible and non-socially responsible, respectively, are in black if stable and in gray if unstable. The inner equilibrium $\left(q_{P}^{*}\left(r_{1}^{*}\right), q_{N}^{*}\left(r_{1}^{*}\right), r_{1}^{*}\right)\left(\operatorname{resp} .\left(q_{P}^{*}\left(r_{2}^{*}\right), q_{N}^{*}\left(r_{2}^{*}\right), r_{2}^{*}\right)\right)$ is represented by a blue (resp. red) curve as $\theta$ increases. For each value of $\theta$ in $[0,1)$, the basin of attraction of the equilibrium $\left(q_{P}^{*}(1), q_{N}^{*}(1), 1\right)$ is represented in green, in yellow that of the equilibrium $\left(q_{P}^{*}(0), q_{N}^{*}(0), 0\right)$, in azure the basin of the interior equilibrium (red curve) and in white the basin of attraction of the inner periodic or chaotic attractor. The bifurcation value $\theta^{1}$ (transcritical bifurcation) for the equilibrium $\left(q_{P}^{*}(1), q_{N}^{*}(1), 1\right)$ is indicated by a black dashed line as well as the bifurcation value $\theta^{0}$ (transcritical bifurcation) for the equilibrium $\left(q_{P}^{*}(0), q_{N}^{*}(0), 0\right)$ as well as the bifurcation values $\theta^{F a}$ and $\theta^{F b}$ (flip bifurcations) for the inner equilibrium. Parameters as in Fig. 1, that is $\alpha=1.9, \gamma=0.01, c_{P}=0.1 ; c_{N}=0.1$ and $\eta=1$. Moreover, $s=3$ and $n=2$ in panel $\mathbf{a}, n=4$ in panel $\mathbf{b}$ and, $n=6$ in panel $\mathbf{c}$. The initial conditions used are $\left(q_{P}^{*}(r)+0.01, q_{N}^{*}(r)+0.01, r\right)$ for all $r \in[0,1]$. The values of $\theta^{F a}$ and $\theta^{F b}$ are detected numerically (colour figure online)

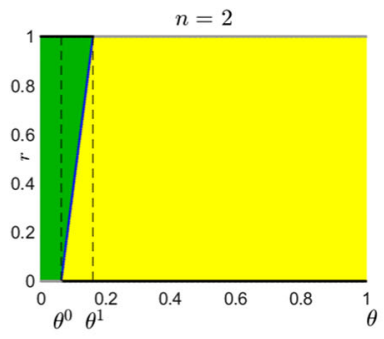

(a)

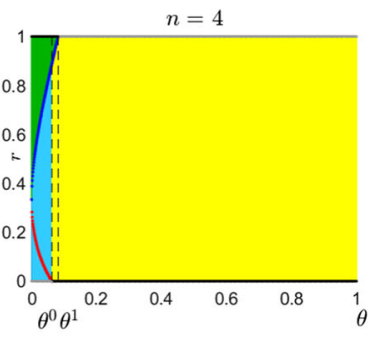

(b)

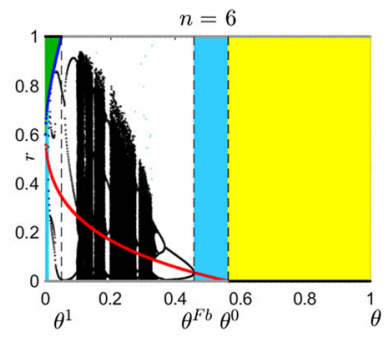

(c)

Fig. 7 Global dynamics of the hybrid model (22)-(23). Bifurcation diagrams with bifurcation parameter $\theta$ varying in $[0,1)$. The border equilibria $\left(q_{P}^{*}(0), q_{N}^{*}(0), 0\right)$ and $\left(q_{P}^{*}(1), q_{N}^{*}(1), 1\right)$, at which all firms are socially responsible and non-socially responsible, respectively, are in black if stable and in gray if unstable. The inner equilibrium $\left(q_{P}^{*}\left(r_{1}^{*}\right), q_{N}^{*}\left(r_{1}^{*}\right), r_{1}^{*}\right)\left(\operatorname{resp} .\left(q_{P}^{*}\left(r_{2}^{*}\right), q_{N}^{*}\left(r_{2}^{*}\right), r_{2}^{*}\right)\right)$ is represented by a blue (resp. red) curve as $\theta$ increases. For each value of $\theta$ in $[0,1)$, the basin of attraction of the equilibrium $\left(q_{P}^{*}(1), q_{N}^{*}(1), 1\right)$ is represented in green, in yellow that of the equilibrium $\left(q_{P}^{*}(0), q_{N}^{*}(0), 0\right)$, in azure the basin of the interior equilibrium (red curve) and in white the basin of attraction of the inner periodic or chaotic attractor. The bifurcation value $\theta^{1}$ (transcritical bifurcation) for the equilibrium $\left(q_{P}^{*}(1), q_{N}^{*}(1), 1\right)$ is indicated by a black dashed line as well as the bifurcation value $\theta^{0}$ (transcritical bifurcation) for the equilibrium $\left(q_{P}^{*}(0), q_{N}^{*}(0), 0\right)$ as well as the bifurcation values $\theta^{F a}$ and $\theta^{F b}$ (flip bifurcations) for the inner equilibrium. Parameters as in Fig. 1, that is $\alpha=1.9, \gamma=0.01, c_{P}=0.1 ; c_{N}=0.1$ and $\eta=1$. Moreover, $s=0.5$ and $n=2$ in panel $\mathbf{a}, n=4$ in panel $\mathbf{b}$ and, $n=6$ in panel $\mathbf{c}$. The initial conditions used are $\left(q_{P}^{*}(r)+0.01, q_{N}^{*}(r)+0.01, r\right)$ for all $r \in[0,1]$. The values of $\theta^{F a}$ and $\theta^{F b}$ are detected numerically (colour figure online)

favor the coordination of boundedly rational firms and helps the system to converge towards the Bayesian-Cournot Nash equilibrium. 


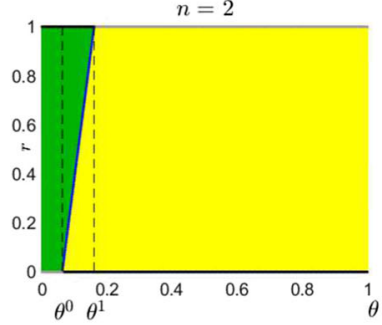

(a)

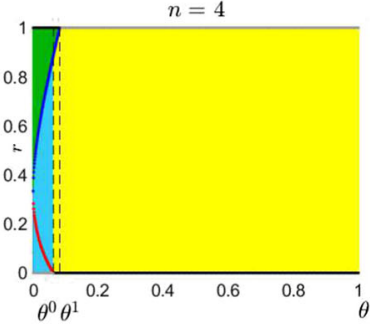

(b)

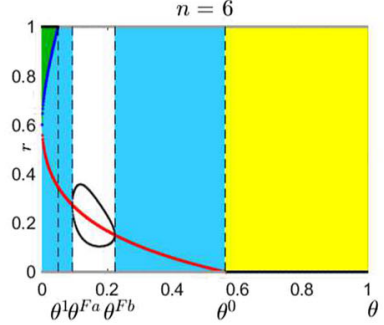

(c)

Fig. 8 Global dynamics of the hybrid model (22)-(23). Bifurcation diagrams with bifurcation parameter $\theta$ varying in $[0,1)$. The border equilibria $\left(q_{P}^{*}(0), q_{N}^{*}(0), 0\right)$ and $\left(q_{P}^{*}(1), q_{N}^{*}(1), 1\right)$, at which all firms are socially responsible and non-socially responsible, respectively, are in black if stable and in gray if unstable. The inner equilibrium $\left(q_{P}^{*}\left(r_{1}^{*}\right), q_{N}^{*}\left(r_{1}^{*}\right), r_{1}^{*}\right)\left(\operatorname{resp} .\left(q_{P}^{*}\left(r_{2}^{*}\right), q_{N}^{*}\left(r_{2}^{*}\right), r_{2}^{*}\right)\right)$ is represented by a blue (resp. red) curve as $\theta$ increases. For each value of $\theta$ in $[0,1)$, the basin of attraction of the equilibrium $\left(q_{P}^{*}(1), q_{N}^{*}(1), 1\right)$ is represented in green, in yellow that of the equilibrium $\left(q_{P}^{*}(0), q_{N}^{*}(0), 0\right)$, in azure the basin of the interior equilibrium (red curve) and in white the basin of attraction of the inner periodic or chaotic attractor. The bifurcation value $\theta^{1}$ (transcritical bifurcation) for the equilibrium $\left(q_{P}^{*}(1), q_{N}^{*}(1), 1\right)$ is indicated by a black dashed line as well as the bifurcation value $\theta^{0}$ (transcritical bifurcation) for the equilibrium $\left(q_{P}^{*}(0), q_{N}^{*}(0), 0\right)$ as well as the bifurcation values $\theta^{F a}$ and $\theta^{F b}$ (flip bifurcations) for the inner equilibrium. Parameters as in Fig. 1, that is $\alpha=1.9, \gamma=0.01, c_{P}=0.1 ; c_{N}=0.1$ and $\eta=1$. Moreover, $s=10$ and $n=2$ in panel $\mathbf{a}, n=4$ in panel $\mathbf{b}$ and, $n=6$ in panel $\mathbf{c}$. The initial conditions used are $\left(q_{P}^{*}(r)+0.01, q_{N}^{*}(r)+0.01, r\right)$ for all $r \in[0,1]$. The values of $\theta^{F a}$ and $\theta^{F b}$ are detected numerically (colour figure online)

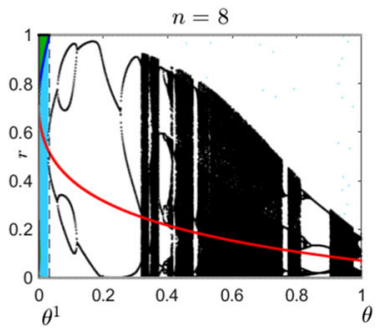

(a)

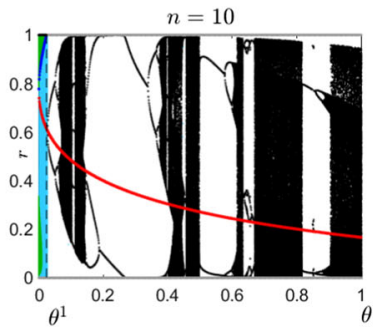

(b)

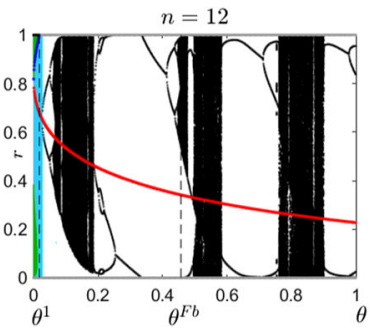

(c)

Fig. 9 Global dynamics of the hybrid model (22)-(23). Bifurcation diagrams with bifurcation parameter $\theta$ varying in $[0,1)$. The border equilibria $\left(q_{P}^{*}(0), q_{N}^{*}(0), 0\right)$ and $\left(q_{P}^{*}(1), q_{N}^{*}(1), 1\right)$, at which all firms are socially responsible and non-socially responsible, respectively, are in black if stable and in gray if unstable. The inner equilibrium $\left(q_{P}^{*}\left(r_{1}^{*}\right), q_{N}^{*}\left(r_{1}^{*}\right), r_{1}^{*}\right)\left(\operatorname{resp} .\left(q_{P}^{*}\left(r_{2}^{*}\right), q_{N}^{*}\left(r_{2}^{*}\right), r_{2}^{*}\right)\right)$ is represented by a blue (resp. red) curve as $\theta$ increases. For each value of $\theta$ in $[0,1)$, the basin of attraction of the equilibrium $\left(q_{P}^{*}(1), q_{N}^{*}(1), 1\right)$ is represented in green, in yellow that of the equilibrium $\left(q_{P}^{*}(0), q_{N}^{*}(0), 0\right)$, in azure the basin of the interior equilibrium (red curve) and in white the basin of attraction of the inner periodic or chaotic attractor. The bifurcation value $\theta^{1}$ (transcritical bifurcation) for the equilibrium $\left(q_{P}^{*}(1), q_{N}^{*}(1), 1\right)$ is indicated by a black dashed line as well as the bifurcation value $\theta^{0}$ (transcritical bifurcation) for the equilibrium $\left(q_{P}^{*}(0), q_{N}^{*}(0), 0\right)$ as well as the bifurcation values $\theta^{F a}$ and $\theta^{F b}$ (flip bifurcations) for the inner equilibrium. Parameters as in Fig. 1, that is $\alpha=1.9, \gamma=0.01, c_{P}=0.1 ; c_{N}=0.1$ and $\eta=1$. Moreover, $s=3$ and $n=8$ in panel $\mathbf{a}, n=10$ in panel $\mathbf{b}$ and, $n=12$ in panel $\mathbf{c}$. The initial conditions used are $\left(q_{P}^{*}(r)+0.01, q_{N}^{*}(r)+0.01, r\right)$ for all $r \in[0,1]$. The values of $\theta^{F a}$ and $\theta^{F b}$ are detected numerically (colour figure online) 


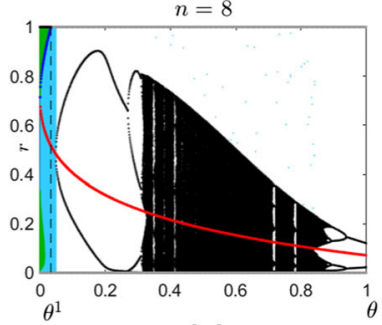

(a)

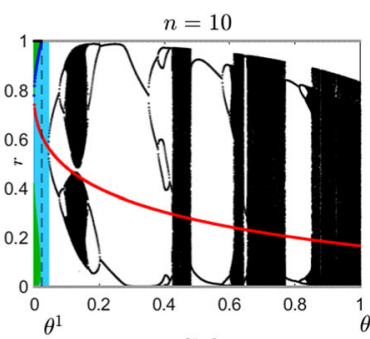

(b)

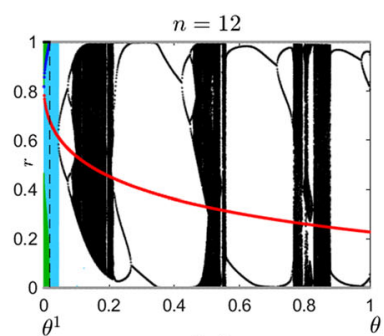

(c)

Fig. 10 Global dynamics of the hybrid model (22)-(23). Bifurcation diagrams with bifurcation parameter $\theta$ varying in $[0,1)$. The border equilibria $\left(q_{P}^{*}(0), q_{N}^{*}(0), 0\right)$ and $\left(q_{P}^{*}(1), q_{N}^{*}(1), 1\right)$, at which all firms are socially responsible and non-socially responsible, respectively, are in black if stable and in gray if unstable. The inner equilibrium $\left(q_{P}^{*}\left(r_{1}^{*}\right), q_{N}^{*}\left(r_{1}^{*}\right), r_{1}^{*}\right)\left(\operatorname{resp} .\left(q_{P}^{*}\left(r_{2}^{*}\right), q_{N}^{*}\left(r_{2}^{*}\right), r_{2}^{*}\right)\right)$ is represented by a blue (resp. red) curve as $\theta$ increases. For each value of $\theta$ in $[0,1)$, the basin of attraction of the equilibrium $\left(q_{P}^{*}(1), q_{N}^{*}(1), 1\right)$ is represented in green, in yellow that of the equilibrium $\left(q_{P}^{*}(0), q_{N}^{*}(0), 0\right)$, in azure the basin of the interior equilibrium (red curve) and in white the basin of attraction of the inner periodic or chaotic attractor. The bifurcation value $\theta^{1}$ (transcritical bifurcation) for the equilibrium $\left(q_{P}^{*}(1), q_{N}^{*}(1), 1\right)$ is indicated by a black dashed line as well as the bifurcation value $\theta^{0}$ (transcritical bifurcation) for the equilibrium $\left(q_{P}^{*}(0), q_{N}^{*}(0), 0\right)$ as well as the bifurcation values $\theta^{F a}$ and $\theta^{F b}$ (flip bifurcations) for the inner equilibrium. Parameters as in Fig. 1, that is $\alpha=1.9, \gamma=0.01, c_{P}=0.1 ; c_{N}=0.1$ and $\eta=1$. Moreover, $s=10$ and $n=8$ in panel $\mathbf{a}, n=10$ in panel $\mathbf{b}$ and, $n=12$ in panel $\mathbf{c}$. The initial conditions used are $\left(q_{P}^{*}(r)+0.01, q_{N}^{*}(r)+0.01, r\right)$ for all $r \in[0,1]$. The values of $\theta^{F a}$ and $\theta^{F b}$ are detected numerically (colour figure online)

\section{Conclusions}

In this paper, a hybrid evolutionary model describes the diffusion of corporate social responsibility (CSR) in an industry characterized by Cournot competition. The diffusion process of corporate social responsibility among firms that play the Bayesian-Cournot Nash equilibrium is modeled by an evolutionary mechanism, which describes the firms' updating belief about the composition of the industry. Customers pay a higher reservation price for products released by socially responsible companies, which may suffer a higher marginal cost due to their socially responsible strategy. Being socially responsible entails donating a fraction of its own profits to finance activities of charitable interest or that mitigate the environmental and social risks associated with the company's business. The investigation reveals that reducing the fraction of profits donated, corporate social responsibility becomes an evolutionarily stable strategy adopted by the entire population of firms. At the same time, the trade-off between net marginal revenues and level of production that affects the profit of a socially responsible firm changes and favors heterogeneity when the size of the oligopoly increases. Moreover, the debated question of the rationality of being socially responsible is investigated by imposing the neutrality of CSR activities. According to this condition, the competitive advantage of being a socially responsible company is offset by the higher costs associated with social activities. Therefore, the literature argues that a firm does not have any convenience for being socially responsible. Despite so, the number of companies worldwide that release CSR reports shows a positive trend, see KPMG (2011). Consistently with these empirical observations, the model indicates that the 
neutrality of CSR activities, imposed when the industry is homogeneously populated by either socially responsible firms or by non-socially responsible firms, implies the evolutionary stability of the CSR strategy.

Relaxing the hypothesis of Nash firms, these results are confirmed in a boundedlyrational setting characterized by firms that follow a partial-adjustment-towardsthe-best-response process instead of producing the Nash quantities. The model is represented by a hybrid dynamical system where the production output evolves in continuous time while beliefs are updated according to a discrete-time process. This mathematical configuration gives rise to hybrid evolutionary games for which the development of a mathematical methodology is the next task of our research agenda.

Acknowledgements The Authors acknowledge the support of the Czech Science Foundation (GACR) under project [20-16701S] and VSB-TU Ostrava under the SGS project SP2020/11.

\section{Compliance with ethical standards}

Conflict of interest The authors declare that they have no conflict of interest.

Open Access This article is licensed under a Creative Commons Attribution 4.0 International License, which permits use, sharing, adaptation, distribution and reproduction in any medium or format, as long as you give appropriate credit to the original author(s) and the source, provide a link to the Creative Commons licence, and indicate if changes were made. The images or other third party material in this article are included in the article's Creative Commons licence, unless indicated otherwise in a credit line to the material. If material is not included in the article's Creative Commons licence and your intended use is not permitted by statutory regulation or exceeds the permitted use, you will need to obtain permission directly from the copyright holder. To view a copy of this licence, visit http://creativecommons.org/licenses/by/4.0/.

\section{Appendix A: Proofs of the main results}

Proof of Theorem 1 Operating a time rescaling $z=\frac{t}{s}$, then $r_{z+1}=G\left(r_{z}\right)$. Therefore, the model in (20) is equivalent to a one-dimensional dynamical system in discrete time. The equilibrium condition $r=G(r)$ is satisfied only for $r=0$, or $r=1$ or $F(r)=0$. Therefore, the possible equilibria of the model are $0,1, r_{1}^{*}$ and $r_{2}^{*}$, with $r_{1}^{*}$ and $r_{2}^{*}$ defined as in (15). The local stability of the equilibria can be investigated by classical eigenvalue analysis. Specifically,

$$
\frac{\partial G}{\partial r}=\frac{r+(1-r) \mathrm{e}^{-\eta F(r)}-r\left(1-\mathrm{e}^{-\eta F(r)}-\eta \frac{\partial F}{\partial r}(r)(1-r) \mathrm{e}^{-\eta F(r)}\right)}{\left(r+(1-r) \mathrm{e}^{-\eta F(r)}\right)^{2}}
$$

where

$$
\begin{aligned}
\frac{\partial F}{\partial r}(r)= & \frac{-2(n-1)^{2}(1-r)\left(1-c_{P}-\alpha+c_{N}\right)^{2}-4\left(1-c_{P}\right)(n-1)\left(1-c_{P}-\alpha+c_{N}\right)}{4 \gamma(n+1)^{2}} \\
& -\theta \frac{2(n-1)^{2} r\left(\alpha-c_{N}-1+c_{P}\right)^{2}+4\left(\alpha-c_{N}\right)(n-1)\left(\alpha-c_{N}-1+c_{P}\right)}{4 \gamma(n+1)^{2}}
\end{aligned}
$$


Then, the eigenvalues associated to the equilibria (one for each equilibrim) are

$$
\begin{aligned}
& \frac{\partial G}{\partial r}(0)=\mathrm{e}^{\eta F(0)}(>0) \\
& \frac{\partial G}{\partial r}(1)=\mathrm{e}^{-\eta F(1)}(>0) \\
& \frac{\partial G}{\partial r}\left(r_{1}^{*}\right)=1+\eta \frac{\partial F}{\partial r}\left(r_{1}^{*}\right)\left(1-r_{1}^{*}\right) r_{1}^{*} \\
& \frac{\partial G}{\partial r}\left(r_{2}^{*}\right)=1+\eta \frac{\partial F}{\partial r}\left(r_{2}^{*}\right)\left(1-r_{2}^{*}\right) r_{2}^{*}
\end{aligned}
$$

and, by standard arguments, the equilibrium 0 is stable for $\frac{\partial G}{\partial r}(0) \in(0,1)$ which is equivalent to impose $\frac{\partial G}{\partial r}(0)<1 \Leftrightarrow \eta F(0)<0$. Since,

$$
F(0)=\frac{4\left(1-c_{p}\right)^{2}+(n-1)^{2}\left(1-c_{P}-\alpha+c_{N}\right)^{2}+4\left(1-c_{p}\right)(n-1)\left(1-c_{P}-\alpha+c_{N}\right)-\theta 4\left(\alpha-c_{N}\right)^{2}}{4 \gamma(n+1)^{2}}
$$

the stability condition $\eta F(0)<0$ for the equilibrium 0 is equivalent to $\theta^{0}<\theta$. On the contrary, by standard arguments the equilibrium 1 is locally asymptotically stable for $\frac{\partial G}{\partial r}(1) \in(0,1)$ which is equivalent to $\frac{\partial G}{\partial r}(1)<1 \Leftrightarrow \eta F(1)>0$. Since

$$
F(1)=\frac{4\left(1-c_{p}\right)^{2}-\theta 4\left(\alpha-c_{N}\right)^{2}-\theta(n-1)^{2}\left(\alpha-c_{N}-1+c_{P}\right)^{2}-\theta 4\left(\alpha-c_{N}\right)(n-1)\left(\alpha-c_{N}-1+c_{P}\right)}{4 \gamma(n+1)^{2}}
$$

the stability condition $\eta F(1)>0$ for the equilibrium 1 is equivalent to $\theta^{1}>\theta$. Concerning $r_{1}^{*}$ and $r_{2}^{*}$, let us note that $F$ is a quadratic and convex function and $r_{1}^{*}>r_{2}^{*}$. Therefore, $\frac{\partial F}{\partial r}\left(r_{1}^{*}\right)>0$ and $\frac{\partial F}{\partial r}\left(r_{2}^{*}\right)<0$. It follows that the equilibrium $r_{1}^{*}$ has an eigenvalue greater than one and is unstable, while $r_{2}^{*}$ has an eigenvalue smaller than one and it is stable when this eigenvalue is also greater than -1 , it is the case for $\theta<\theta^{F}$, it undergoes a bifurcation of eigenvalue -1 (flip bifurcation) at $\theta=\theta^{F}$, and it is unstable otherwise. Further note that $r_{1}^{*}$ and $r_{2}^{*}$ are real for $\theta \geq 0$ (they appear through a saddle-node bifurcation at $\theta^{S N}=0$ ), see (15). Using these results, consider the case $\theta<\underline{\theta}$ and assume that the condition (18) is not satisfied. Then, $F(0)>0, F(1)>0$ and $r_{1,2}^{*}(0) \notin[0,1]$. We can prove that $r_{1,2}^{*}(\theta) \notin[0,1]$ for each $\theta \in[0, \underline{\theta})$. In fact, by the continuity of $r_{1,2}^{*}(\theta)$ w.r.t. $\theta$ in $[0,1)$, when (18) is not satisfied the existence of some $\theta<\underline{\theta}$ for which at least one of $r_{1,2}^{*}(\theta)$ is in $[0,1]$ implies either $F(0)=0$ or $F(1)=0$, which contradicts the property $F(0)>0$ and $F(1)>0$ when $\theta \in[0, \underline{\theta})$. Therefore, $F(r)>0$ for all $r \in[0,1]$ when $\theta<\underline{\theta}$ and condition (18) is not satisfied. This implies $G(r)>r$ for all $r \in(0,1)$ which, since $G([0,1])=[0,1]$, is sufficient to have $\mathcal{B}(1)=\left(r_{1}^{*}, 1\right]$. Consider now the case $\theta<\underline{\theta}$ and condition (18) satisfied. Then, $r_{1,2}^{*}(\theta) \in(0,1)$ for $\theta=0$ and being continuous functions of $\theta$ they can exit $[0,1]$ only by crossing either 0 or 1 but this implies either $F(0)=0$ or $F(1)=0$, respectively, which is not possible for $\theta<\underline{\theta}$. Therefore, $r_{1,2}^{*}(\theta) \in(0,1) \forall \theta<\underline{\theta}$ and $F(r)>0$ for $r \in\left(r_{1}^{*}(\theta), 1\right)$ follows by the continuity of $F$ and $F(0)>0$. Since $G([0,1])=[0,1]$, we then have that $\left(r_{1}^{*}(\theta), 1\right)$ is a portion of the basin of attraction of the equilibrium 1 . The stability of $r_{2}^{*}$ follows by the eigenvalue analysis above. This completes the proof of point 1 . Concerning the 
second point. Here we distinguish two cases: $\theta^{0}>\theta^{1}$ and $\theta^{1}>\theta^{0}$. In case $\theta^{0}>\theta^{1}$, for $\theta \in(\underline{\theta}, \bar{\theta})=\left(\theta^{1}, \theta^{0}\right)$ we have $F(0)>0>F(1)$. Then by continuity of function $F$ in $[0,1]$ one and only one inner equilibrium exists. Note again that $F$ is a quadratic and convex function. Hence, the unique inner equilibrium is $r_{2}^{*}$ and by eigenvalues analysis we know that it is locally asymptotically stable for $\theta<\theta^{F}$, it loses stability through a flip bifurcation at $\theta=\theta^{F}$ and is unstable for $\theta>\theta^{F}$. Moreover, by standard results in bifurcation theory a periodic attractor must exist for $\theta$ slightly larger than $\theta^{F}$, a numerical test confirms that such attractor exists. This complete the proof of the first sub-point of point two. In case $\theta^{1}>\theta^{0}$, for $\theta \in(\underline{\theta}, \bar{\theta})=\left(\theta^{0}, \theta^{1}\right)$ we have $F(1)>0>F(0)$. Then, by continuity of function $F$ we have that one and only one inner equilibrium exists in $[0,1]$. Note again that $F$ is a quadratic and convex function. Hence, the unique inner equilibrium is $r_{1}^{*}$ and by eigenvalues analysis we know that it is unstable. At the same time, by eigenvalue analysis we know that 0 and 1 are stable equilibria. Since by continuity $F(r)>r$ (resp. $F(r)<r$ ) for $r>r_{1}^{*}$ (resp. $r<r_{1}^{*}$ ), then $G(r)>r$ (resp. $G(r)<r$ ) for $r>r_{1}^{*}\left(\right.$ resp. $r<r_{1}^{*}$ ). Invoking the fact that $[0,1]$ is an invariant set, this is enough to conclude that $\mathcal{B}(0)=\left[0, r_{1}^{*}\right)$ and $\mathcal{B}(1)=\left(r_{1}^{*}, 1\right]$, which proves the second sub-point of point two. Consider now the case $\theta>\bar{\theta}$. Then, $F(1)$ and $F(0)$ are both negative. By eigenvalue analysis, see above, we know that 0 is locally asymptotically stable while 1 is unstable. Moreover, since $F$ is a quadratic and convex function we have that $r_{2}^{*}<0, r_{1}^{*}>1$ and $F(r)<0$ for all $r \in[0,1]$, which implies $G(r)<r$ for all $r \in[0,1]$. Then, by the invariance of $G$ w.r.t. $[0,1]$ we can conclude that $\mathcal{B}(0)=[0,1)$. This completes the proof of point 3 and the proof of the Theorem.

Proof of Theorem 2 Consider $r^{*}$ to be an equilibrium of the model (20) and $q_{P}^{*}\left(r^{*}\right)$ and $q_{N}^{*}\left(r^{*}\right)$ defined as in (11). Then $B R_{P}\left(q_{P}^{*}\left(r^{*}\right)\right)=q_{P}^{*}\left(r^{*}\right)$ and $B R_{N}\left(q_{P}^{*}\left(r^{*}\right)\right)=$ $q_{P}^{*}\left(r^{*}\right)$ by definition of $q_{P}^{*}\left(r^{*}\right)$ and $q_{N}^{*}\left(r^{*}\right)$, which implies $q_{P, t}=q_{P}^{*}\left(r^{*}\right)$ and $q_{N, t}=$ $q_{N}^{*}\left(r^{*}\right)$ for any $t \in(s(m-1), s m)$ when $q_{P, s(m-1)}=q_{P}^{*}\left(r^{*}\right)$ and $q_{N, s(m-1)}=$ $q_{N}^{*}\left(r^{*}\right)$. Then $\bar{\pi}_{N, s m}-\bar{\pi}_{P, s m}=F\left(r^{*}\right)$, with $F\left(r^{*}\right)$ which is equal to zero since $r^{*}$ is by hypothesis an equilibrium of model (20). Thus $\left(q_{P}^{*}\left(r^{*}\right), q_{N}^{*}\left(r^{*}\right), r^{*}\right)$ is an equilibrium of the hybrid model. Assume now that $\left(q_{P}^{*}\left(r^{*}\right), q_{N}^{*}\left(r^{*}\right), r^{*}\right)$ is an equilibrium of the hybrid model (22)-(23). Then, $\bar{\pi}_{N, t}-\bar{\pi}_{P, t}=0$ and $\bar{\pi}_{N, t}-\bar{\pi}_{P, t}=F\left(r^{*}\right)$, which implies that $r^{*}$ is an equilibrium of model (20). To complete the proof, consider $\left(q_{P}^{+}\left(r^{+}\right), q_{N}^{+}\left(r^{+}\right), r^{+}\right)$, with $r^{+}$which is not an equilibrium for the model (20), then $\bar{\pi}_{N, s m}-\bar{\pi}_{P, s m}=F\left(r^{+}\right)=0$, which contradicts the hypothesis that $r^{+}$is not an equilibrium of model (20). Moreover, consider $\left(q_{P}^{+}\left(r^{*}\right), q_{N}^{+}\left(r^{*}\right), r^{*}\right)$ a generic equilibrium of the hybrid model (22)-(23), with $q_{P}^{+}\left(r^{*}\right) \neq q_{P}^{*}\left(r^{*}\right)$ and $q_{N}^{+}\left(r^{*}\right) \neq q_{N}^{*}\left(r^{*}\right)$ but $r^{*}$ which is an equilibrium of model (20). Then $B R_{N}\left(q_{N}^{+}\left(r^{*}\right)\right)=q_{N}^{+}\left(r^{*}\right)$ and $B R_{P}\left(q_{N}^{+}\left(r^{*}\right)\right)=q_{N}^{+}\left(r^{*}\right)$. Since $B R_{N}\left(q_{N}^{*}\left(r^{*}\right)\right)=q_{N}^{*}\left(r^{*}\right)$ and $B R_{P}\left(q_{N}^{*}\left(r^{*}\right)\right)=$ $q_{N}^{*}\left(r^{*}\right)$ as well, see the definition of $q_{P}^{*}\left(r^{*}\right)$ and $q_{N}^{*}\left(r^{*}\right)$ in (11), the linearity of the last system of two equations implies that $q_{P}^{+}\left(r^{*}\right)=q_{P}^{*}\left(r^{*}\right)$ and $q_{N}^{+}\left(r^{*}\right)=q_{N}^{*}\left(r^{*}\right)$ which contradicts the hypothesis $q_{P}^{+}\left(r^{*}\right) \neq q_{P}^{*}\left(r^{*}\right)$ and $q_{N}^{+}\left(r^{*}\right) \neq q_{N}^{*}\left(r^{*}\right)$. This completes the proof of the Theorem.

Proof of Lemma 3 Since $F$ is a convex function and $F(1)=F(0)=0$ by hypothesis, it follows that $F(r)<0$ for all $r \in(0,1) . F(r)<0$ implies $r<G(r)$ for all 
$r \in(0,1)$. Then, noting that $[0,1]$ is invariant for $G$ it follows that $\mathcal{B}(0)=[0,1)$. Consider $q_{N}^{*}(r)$ and $q_{P}^{*}(r)$ as in (11), then $q_{N}^{*}(0)>q_{P}^{*}(1)$ follows from Assumption 1. Moreover, by hypothesis $F(1)=F(0)=0$, which implies $\pi_{P}^{*}(0)=\theta \pi_{N}^{*}(0)$ and $\pi_{P}^{*}(1)=\theta \pi_{N}^{*}(1)$. Since $q_{N}^{*}(1)>q_{N}^{*}(0)>0$, see $(11)$, it follows that $\pi_{N}^{*}(1)=$ $\gamma\left(q_{N}^{*}(1)\right)^{2}>\pi_{N}^{*}(0)=\gamma\left(q_{N}^{*}(0)\right)^{2}$. Hence, $\pi_{P}^{*}(1)>\theta \pi_{N}^{*}(0)$. This completes the proof of the Lemma.

\section{References}

Arya A, Mittendorf B (2015) Supply chain consequences of subsidies for corporate social responsability. Prod Oper Manag 24(8):1346-1357

Aupperle KE, Carroll AB, Hatfield JD (1985) An empirical examination of the relationship between corporate social responsibility and profitability. Acad Manag 28(2):446-463

Belkaoui A (1976) The impact of the disclosure of the environmental effects of organizational behavior on the market. Financ Manag 5(4):26-31

Bendle N, Vandenbosch M (2014) Competitor orientation and the evolution of business markets. Market Sci 33(6):781-795

Bischi GI, Chiarella C, Kopel M, Szidarovszky F (2010) Nonlinear oligopolies: stability and bifurcations. Springer, Berlin

Bischi GI, Lamantia F, Radi D (2013a) Multi-species exploitation with evolutionary switching of harvesting strategies. Nat Resour Model 26(4):546-571

Bischi GI, Lamantia F, Radi D (2013b) A prey-predator model with endogenous harvesting strategy switching. Appl Math Comput 219(20):10,123-10,142

Bischi GI, Lamantia F, Radi D (2015) An evolutionary Cournot model with limited market knowledge. J Econ Behav Organ 116:219-238

Dahlsrud A (2008) How corporate social responsibility is defined: an analysis of 37 definitions. Corp Soc Responsib Environ Manag 15(1):1-13

Droste E, Hommes CH, Tuinstra J (2002) Endogenous fluctuations under evolutionary pressure in Cournot competition. Games Econ Behav 40(2):232-269

Elkington J (1994) Towards the sustainable corporation: win-win-win business strategies for sustainable development. Calif Manag Rev 36(2):90-100

Friedman M (1970) The social responsibility of business is to increase its profits. The New York Times September 13

Gosselt JF, van Rompay T, Haske L (2017) Won't get fooled again: the effects of internal and external CSR ECO-labeling. J Bus Ethics 155:413-424

Häckner J (2000) A note on price and quantity competition in differentiated oligopolies. J Econ Theory 93:233-239

Harsanyi JC (1973) Games with randomly disturbed payoffs: a new rationale for mixed-strategy equilibrium points. Int J Game Theory 2:1-23

Hart SL, Ahuja G (1996) Does it pay to be green? An empirical examination of the relationship between emission reduction and firm performance. Bus Strategy Environ 5(1):30-37

Heifetz A, Shannon C, Spiegel Y (2007) What to maximize if you must. J Econ Theory 133(1):31-57

Hillman A, Keim G (2001) Shareholder value, stakeholder management, and social issues: What's the bottom line? Strateg Manag J 22:125-139

Hofbauer J, Sigmund K (2003) Evolutionary game dynamics. Bull (New Ser) Am Math Soc 40(4):479-519

Hommes CH, Ochea MI, Tuinstra J (2018) Evolutionary competition between adjustment processes in Cournot oligopoly: Instability and complex dynamics. Dyn Games Appl 8:822-843

Jiang B, Srinivasan K (2016) Pricing and persuasive advertising in a differentiated market. Market Lett 27:579-588

Koçkesen L, Ok E, Sethi R (2000) The strategic advantage of negatively interdependent preferences. J Econ Theory 92:274-299

Königstein M, Müller W (2001) Why firms should care for customers. Econ Lett 72(1):47-52

Kopel M, Brand B (2012) Socially responsible firms and endogenous choice of strategic incentives. Econ Model 29(3):982-989 
Kopel M, Lamantia F (2018) The persistence of social strategies under increasing competitive pressure. J Econ Dyn Control 91:71-83

Kopel M, Lamantia F, Szidarovszky F (2014) Evolutionary competition in a mixed market with socially concerned firms. J Econ Dyn Control 48:394-409

KPMG (2011) International survey of corporate social responsibility reporting. Tech. Rep

Lamantia F, Radi D (2015) Exploitation of renewable resources with differentiated technologies: an evolutionary analysis. Math Comput Simul 108:155-174

Manasakis C, Mitrokostas E, Petrakis E (2014) Strategic corporate social responsibility activities and corporate governance in imperfectly competitive markets. Manag Decision Econ 35(7):460-473

Marcus A (1989) The deterrent to dubious corporate behavior: profitability, probability and safety recalls. Strateg Manag J 10(3):233-250

McFadden D (1980) Econometric models for probabilistic choice among products. J Bus 53(3):S19-S29

Piga C (2002) Corporate social responsibility: a theory of the firm perspective- a few comments and some suggested extensions. Acad Manag Rev 27(1):13-15

Porter M, Kramer M (2002) The competitive advantage of corporate philanthropy. Harv Bus Rev 80:56-69

Riahi-Belkaoui A (1992) Executive compensation, organizational effectiveness, social performance and firm performance: An empirical investigation. J Bus Finance Account 19(1):25-38

Seitanidi M, Crane A (2009) Implementing CSR through partnerships: understanding the selection, design and institutionalisation of nonprofit-business partnerships. J Bus Ethics 85:413-429

Smith C (1994) The new corporate philanthropy. Harv Bus Rev 72(3):105-116

Testa F, Iraldo F, Vaccari A, Ferrari E (2015) Why eco-labels can be effective marketing tools: evidence from a study on Italian consumers. Bus Strategy Environ 24(4):252-265

Vance S (1975) Are socially responsible firms good investment risks? Manag Rev 64:18-24

Williams AM, Siegel D, Wright P (2006) Corporate social responsibility: strategic implications. J Manag Stud 43(1):1-18

Publisher's Note Springer Nature remains neutral with regard to jurisdictional claims in published maps and institutional affiliations.

\section{Affiliations}

\section{Tomáš Tichý ${ }^{1} \cdot$ Davide Radi $^{1,2} \cdot$ Fabio Lamantia ${ }^{1,3}$}

$凶$ Fabio Lamantia

fabio.lamantia@vsb.cz; fabio.lamantia@unical.it

Tomáš Tichý

tomas.tichy@vsb.cz

Davide Radi

davide.radi@vsb.cz; davide.radi@unipi.it

1 Department of Finance, VŠB-Technical University of Ostrava, Ostrava, Czech Republic

2 Department of Economics and Management, University of Pisa, Pisa, Italy

3 Department of Economics, Statistics and Finance, University of Calabria, Rende, Italy 